\title{
Membrane Association Modes of Natural Anticancer Peptides: Mechanistic Details on Helicity, Orientation, and Surface Coverage
}

\author{
Mayra Quemé-Peña ${ }^{1,2}{ }^{\mathbb{D}}$, Tünde Juhász ${ }^{1, *}$, Gergely Kohut ${ }^{1,2}{ }^{\mathbb{D}}$, Maria Ricci ${ }^{1}$, Priyanka Singh ${ }^{1,2}$, \\ Imola Cs. Szigyártó ${ }^{1}{ }^{(\mathbb{D}}$, Zita I. Papp ${ }^{3}{ }^{\mathbb{D}}$, Lívia Fülöp ${ }^{3}{ }^{\mathbb{D}}$ and Tamás Beke-Somfai ${ }^{1, *}$
}

1 Biomolecular Self-Assembly Research Group, Institute of Materials and Environmental Chemistry, Research Centre for Natural Sciences, Magyar Tudósok Körútja 2, H-1117 Budapest, Hungary; mayra.queme@ttk.hu (M.Q.-P.); kohut.gergely@ttk.mta.hu (G.K.); dr.mariaricci@gmail.com (M.R.); priyanka.singh@ttk.hu (P.S.); szigyarto.imola.csilla@ttk.hu (I.C.S.)

2 Hevesy György Ph.D. School of Chemistry, ELTE Eötvös Loránd University, Pázmány Péter Sétány 1/A, H-1117 Budapest, Hungary

3 Department of Medical Chemistry, University of Szeged, Dóm tér 8, H-6720 Szeged, Hungary; papp.ibolya.zita@med.u-szeged.hu (Z.I.P.); fulop.livia@med.u-szeged.hu (L.F.)

* Correspondence: juhasz.tunde@ttk.hu (T.J.); beke-somfai.tamas@ttk.hu (T.B.-S.)

Citation: Quemé-Peña, M.; Juhász, T.; Kohut, G.; Ricci, M.; Singh, P.; Szigyártó, I.C.; Papp, Z.I.; Fülöp, L.; Beke-Somfai, T. Membrane

Association Modes of Natural Anticancer Peptides: Mechanistic Details on Helicity, Orientation, and Surface Coverage. Int. J. Mol. Sci. 2021, 22, 8613. https://doi.org/ $10.3390 /$ ijms 22168613

Academic Editors: Nuno C. Santos and Sónia Gonçalves

Received: 1 July 2021

Accepted: 6 August 2021

Published: 10 August 2021

Publisher's Note: MDPI stays neutral with regard to jurisdictional claims in published maps and institutional affiliations.

Copyright: (c) 2021 by the authors. Licensee MDPI, Basel, Switzerland. This article is an open access article distributed under the terms and conditions of the Creative Commons Attribution (CC BY) license (https:// creativecommons.org/licenses/by/ $4.0 /)$

\begin{abstract}
Anticancer peptides (ACPs) could potentially offer many advantages over other cancer therapies. ACPs often target cell membranes, where their surface mechanism is coupled to a conformational change into helical structures. However, details on their binding are still unclear, which would be crucial to reach progress in connecting structural aspects to ACP action and to therapeutic developments. Here we investigated natural helical ACPs, Lasioglossin LL-III, Macropin 1, TemporinLa, FK-16, and LL-37, on model liposomes, and also on extracellular vesicles (EVs), with an outer leaflet composition similar to cancer cells. The combined simulations and experiments identified three distinct binding modes to the membranes. Firstly, a highly helical structure, lying mainly on the membrane surface; secondly, a similar, yet only partially helical structure with disordered regions; and thirdly, a helical monomeric form with a non-inserted perpendicular orientation relative to the membrane surface. The latter allows large swings of the helix while the N-terminal is anchored to the headgroup region. These results indicate that subtle differences in sequence and charge can result in altered binding modes. The first two modes could be part of the well-known carpet model mechanism, whereas the newly identified third mode could be an intermediate state, existing prior to membrane insertion.
\end{abstract}

Keywords: anticancer peptides; flow-linear dichroism; molecular dynamics; spectroscopy; peptide conformation

\section{Introduction}

Naturally occurring antimicrobial peptides (AMPs), or host-defence peptides (HDPs), represent one of the first evolved and successful forms of chemical defence for eukaryotic cells against bacteria, protozoa, fungi and viruses [1]. AMPs appear to have remained effective against specific pathogenic organisms over evolutionary time scales and have attracted increasing interest both in terms of their mechanisms of action and as a potential new source of designer molecules to address the growing threat of antimicrobial resistance. During the past decades, the research on antimicrobial peptides (AMPs) has revealed that some of them, termed anticancer peptides (ACPs), also show anticancer activity [2,3]. This is important, because according to the World Health Organization (WHO) [4], cancer remains a major cause of mortality, being the second leading cause of death for people above 70 years, in roughly half of the studied countries. These data point to insufficient current cancer treatments since most cancers cannot be permanently cured. Considerable 
progress has been achieved in respect to therapies [5], including chemotherapy, radiation, or hormone ablation [6,7]. However, severe side effects in normal cells and tissues caused by the insufficient specificity towards cancer cells are often obstacles to the clinical use of conventional therapeutics [5]. Therefore, novel treatment options with increased specificity are needed. ACP-based therapeutics have attracted great interest as drug candidates, offering many advantages due to their unique mechanisms of action, which can provide highly selective inhibition of tumour cell proliferation, migration, and tumour angiogenesis [6,8]. Over the past two decades, the number of ACPs entering the market or tested in clinical trials has been increasing $[9,10]$. In this respect, natural ACPs isolated from animals (including humans and amphibians), plants, and microorganisms are of great interest. In general, ACPs are short peptides, 5 to 40 residues in length, with high hydrophobicity and a net positive charge typically from +2 to +9 . Electrostatic interactions between cationic ACPs and anionic cell membrane components are believed to be a key factor in their selectivity toward cancer cells. In addition, hydrophobic interactions also play important roles; thus, the delicate balance of the multiple effects could remarkably enhance the anticancer activity of ACPs [3,6].

However, despite the huge number of peptide sequences assumed to target lipid bilayers [11], and the extensive research on membrane-active AMPs and ACPs owing to the complexity of membrane-peptide systems, the exact molecular mechanistic details of how specific peptides associate with membranes and fulfil their function are still poorly understood. Further increasing the details is crucial to rationalizing ACP development processes and lowering the role of serendipity in identifying potent novel sequences. In general, ACPs can kill cancer cells mainly via cell membrane disruption mechanisms, similarly to how most AMPs exert function on microorganisms. Membrane disintegration by classical AMPs can occur through various general models, identified earlier and used throughout the field, such as pore formation in the lipid membrane (barrel stave and toroidal pore models), thinning of the membrane bilayer, membrane dissolution (carpet model), or lipid-peptide domain formation, membrane permeabilization, translocation across the membrane, and membrane-lysing [2,3,12-17]. Most of these functions are executed by the peptides in a helical secondary structure, and by now, biophysical studies have shown that many ACPs undergo a structural change from random to helical conformation upon being associated with a preferred lipid bilayer [2,18-20]. However, to reach control of desired membrane functionalities for future compounds and a better understanding of ACP membrane insertion, disruption mechanisms, interactions with associated surface proteins, oligomer formation preceding compromise of membrane integrity, etc., further structural details are needed.

For progress here, we aimed to provide further subtle details beyond the formation of helical structures and set out to characterize the membrane-association mechanism of ACPs by employing combined theoretical and experimental biophysics, as well as improved model membranes. We selected five peptides (Table 1) that have demonstrated anticancer activity but for which mechanistic aspects have not been addressed yet in detail. To maintain a representative selection, those which are from natural sources and show membranolytic activities [2] were selected. At the same time, they differ in length, net charge, and origin (Scheme 1A). Lasioglossin LL-III [1,21-24] (or Lasio III) and the Macropin 1 [24-26] (or Macro1) are components of hymenopteran venom. Venoms of arthropods are a rich source of biologically active and pharmacologically interesting compounds [21]. Lasio III and Macro1 showed low or moderate haemolytic activity [24], and their effect on cancer cells has also been addressed (Table 2), but detailed information on their mechanism is lacking. Temporin-La [27-29] (or Tempo-La) is present in the skin of the frog Rana temporaria. Amphibians are the first group of multicellular organisms connecting water and land, and as a result, they developed excellent chemical defence systems composed of antimicrobial peptides [28]. Tempo-La was reported to inhibit the growth of various Gram-positive bacteria and cancer cells (Table 2) without damaging membranes of healthy mammalian cells [27]; however, the mechanism on how this peptide works remained to be 
elucidated. Finally, the human cathelicidin peptide, LL-37 [30-34], and its active fragment FK-16 are also involved [35,36]. LL-37 is a potent tumour suppressing peptide, and its ability to disrupt cell membranes has been demonstrated in several studies (Table 2). In this case, we use the full-length peptide as a reference to evaluate the potency of its fragment, as better activity against prokaryotes and nucleated cells was reported for FK-16 than for the precursor LL-37 [35,37,38].

Besides the selection of ACPs, it also had to be considered what peptide preferences towards cancer cells are related to the properties of the target membranes, such as membrane fluidity. Indeed, the membrane fluidity of cancer cells is greater than that of untransformed cells [39], which may enhance the lytic activity of ACPs by facilitating membrane destabilization. In contrast to normal mammalian cell membranes, which are mainly composed of neutral zwitterionic phospholipids, such as phosphatidylcholine (PC) [40], cancer cell membranes typically carry a net negative charge due to a higher than normal expression of anionic molecules. Among the latter, phosphatidylserine (PS) constitutes 3-9\% of the total phospholipids of the membrane, and increasing evidence indicates that the exposure of PS on the outer leaflet could not only serve as a cancer cell marker [41] but also plays a key role in the selectivity of ACPs [42]. Hence, besides standard negatively charged vesicles, we employed PS in model membranes mimicking cancer cells (Scheme 1B). Moreover, to improve our understanding, extracellular vesicles (EVs), natively containing PS in the outer leaflet [43], were also exploited to study ACP action. EVs are lipid bilayer-enclosed vesicles produced by the human body that are extensively studied due to their important roles in intercellular communication [44], in diagnostics as biomarkers [45], and in therapeutic applications [46].

The combination of the above sets of compounds and approaches revealed novel details on membrane-associated helical ACPs, allowing us to allocate binding modes into categories. The structural and mechanistic insight provided here contributes to further understanding of the AMP/ACP mechanism of action.

Table 1. Properties of selected natural anticancer peptides used in the study.

\begin{tabular}{|c|c|c|c|c|c|c|c|}
\hline Peptide & Family & Origin & Sequence $^{\mathrm{a}}$ & Length (aa) & Net Charge $^{b}$ & $<\mathrm{H}>^{\mathrm{c}}$ & $<\mu_{H}>^{\mathrm{d}}$ \\
\hline LASIO III & Lasioglossins & $\begin{array}{c}\text { Lasioglossum laticeps } \\
\text { (hymenopteran venom) }\end{array}$ & VNWKKILGKIIKVVK & 15 & +6 & 0.54 & 0.77 \\
\hline MACRO1 & Macropins & $\begin{array}{c}\text { Macropis fulvipes } \\
\text { (hymenopteran venom) }\end{array}$ & GFGMALKLLKKVL & 13 & +4 & 0.57 & 0.54 \\
\hline TEMPO-LA & Temporins & $\begin{array}{c}\text { Rana temporaria } \\
\text { (anuran skin) }\end{array}$ & LLRHVVKILEKYL & 13 & +3 & 0.49 & 0.73 \\
\hline FK-16 & Cathelicidins & $\begin{array}{l}\text { Derived from the peptide } \\
\text { LL-37 }\end{array}$ & FKRIVQRIKDFLRNLV & 16 & +5 & 0.32 & 0.78 \\
\hline LL-37 & Cathelicidins & $\begin{array}{l}\text { Homo sapiens } \\
\text { (human) }\end{array}$ & $\begin{array}{c}\text { LLGDFFRKSKEKIGKE } \\
\text { FKRIVQRIKDFLRNLV } \\
\text { PRTES }^{\text {e }}\end{array}$ & 37 & +6 & $\begin{array}{l}0.23^{\mathrm{f}} \\
0.16^{\mathrm{g}} \\
0.27^{\mathrm{h}}\end{array}$ & $\begin{array}{l}0.60^{f} \\
0.73^{g} \\
0.49^{h}\end{array}$ \\
\hline
\end{tabular}

${ }^{\mathbf{a}} \mathrm{C}$-terminus of the peptides is amidated. ${ }^{\mathbf{b}}$ At neutral $\mathrm{pH} .{ }^{\mathbf{c}}$ The mean hydrophobicity of each peptide was calculated as the average of hydrophobicities of each amino acid in the peptide chain assuming an $\alpha$-helix and a segment of 11-residue window (average values), according to its octanol/water partition according to the scale of Fauchère, J., and Pliska, V [47], using the software HELIQUEST [48]. ${ }^{\mathbf{d}}$ The mean hydrophobic moment used to quantify the amphipathicity of the peptides was calculated according to the equation of Eisenberg et al. [49,50], assuming an $\alpha$-helix and a segment of 11-residue window (average values), using the software HELIQUEST [48]. ${ }^{\mathbf{e}}$ The region corresponding to the fragment FK-16 is in bold. ${ }^{\mathrm{f}}$ Corresponding to the $1-11$ residues of the sequence. ${ }^{\mathrm{g}}$ Corresponding to the 13-24 residues of the sequence. ${ }^{\mathrm{h}}$ Corresponding to the 25-36 residues of the sequence. (Additional information on these compounds can be found in the materials and methods section). 
Table 2. Activity and proposed mechanism of selected natural anticancer peptides used in the study.

\begin{tabular}{|c|c|c|c|c|c|}
\hline Peptide & Antibacterial Mechanism & $\begin{array}{l}\text { Proposed Anticancer } \\
\text { Mechanism }\end{array}$ & Cancer Cell Line ${ }^{a}$ & $\begin{array}{l}\text { Haemolytic } \\
\text { Activity b } \\
(\mathrm{LC} 50[\mu \mathrm{M}]) \\
\end{array}$ & Reference \\
\hline LASIO III & $\begin{array}{l}\text { Outer and inner membrane } \\
\text { permeabilization. }\end{array}$ & $\begin{array}{l}\text { Cell membrane penetration } \\
\text { and enter cells. }\end{array}$ & $\begin{array}{c}\text { PC12, L1210, } \\
\text { CCRF-CEM T, HL-60, } \\
\text { HeLa S3, SW480 }\end{array}$ & $>220$ & [21-24] \\
\hline MACRO1 & $\begin{array}{l}\text { Membrane disruption and cell } \\
\text { penetration. Permeabilization } \\
\text { of the bacterial cell membrane. }\end{array}$ & - & $\begin{array}{l}\text { CCRF-CEM, HeLa S3, } \\
\text { SW480 }\end{array}$ & $\sim 165$ & {$[22,24-26]$} \\
\hline TEMPO-LA & $\begin{array}{l}\text { Insertion into the plasma } \\
\text { membrane. }\end{array}$ & Electrostatic interactions. & $\begin{array}{c}\text { HeLa S3, SM MC7721, } \\
\text { BEL-7402, A549, } \\
\text { SW1116, HepG-2, } \\
\text { BGC-823, HL-7702, } \\
\text { HEK-293T }\end{array}$ & $>250$ & {$[2,27-29]$} \\
\hline FK-16 & $\begin{array}{l}\text { Increased } \\
\text { permeabilization of the } \\
\text { membrane. }\end{array}$ & $\begin{array}{l}\text { Induces cell death by both } \\
\text { caspase-independent } \\
\text { apoptosis and autophagy. }\end{array}$ & LoVo, HCT116, HT-29 & $\sim 125^{\mathrm{c}}$ & {$[35,37,51-53]$} \\
\hline LL-37 & $\begin{array}{c}\text { Targets } \\
\text { anionic bacterial membranes } \\
\text { via the carpet or } \\
\text { toroidal pore model. }\end{array}$ & $\begin{array}{l}\text { Induces apoptosis } \\
\text { and depends mostly on the } \\
\text { ability to act as a ligand for } \\
\text { different membrane receptors } \\
\text { whose expression varies on } \\
\text { different cancer cells. }\end{array}$ & $\begin{array}{c}\text { HT-29, HCT116, } \\
\text { SW1116, SW620, SW480, } \\
\text { LoVo, AGS, TMK1, } \\
\text { Jurkat }\end{array}$ & $>70$ & {$[37,38,51,54-61]$} \\
\hline
\end{tabular}

a Cell lines: Pheochromocytoma of the rat adrenal medulla (PC12), mouse lymphocytic leukaemia (L1210), human lymphoblastic leukaemia (CCRF-CEM T), human promyelocytic leukaemia (HL-60), human cervix carcinoma (HeLa S3), human colon adenocarcinoma (SW480), human hepatocarcinoma (SM MC-7721), human lung adenocarcinoma epithelial (A549), human colorectal carcinoma (SW1116), human gastric carcinoma (BGC-823), human hepatocellular liver carcinoma (HepG2), human embryonic kidney (HEK 293T), human liver (HL-7702), human colon cancer (LoVo), (HCT116), (HT-29) and (SW620), human gastric adenocarcinoma (AGS), gastric adenocarcinoma (TMK1), human T leukaemia (Jurkat). ${ }^{b^{2}} \mathrm{LC}_{50}$ refers to the lytic concentration, i.e., the concentration at which $50 \%$ of erythrocytes are lysed. c Exhibited $13.61 \pm 3.29 \%$ lysis at that concentration.

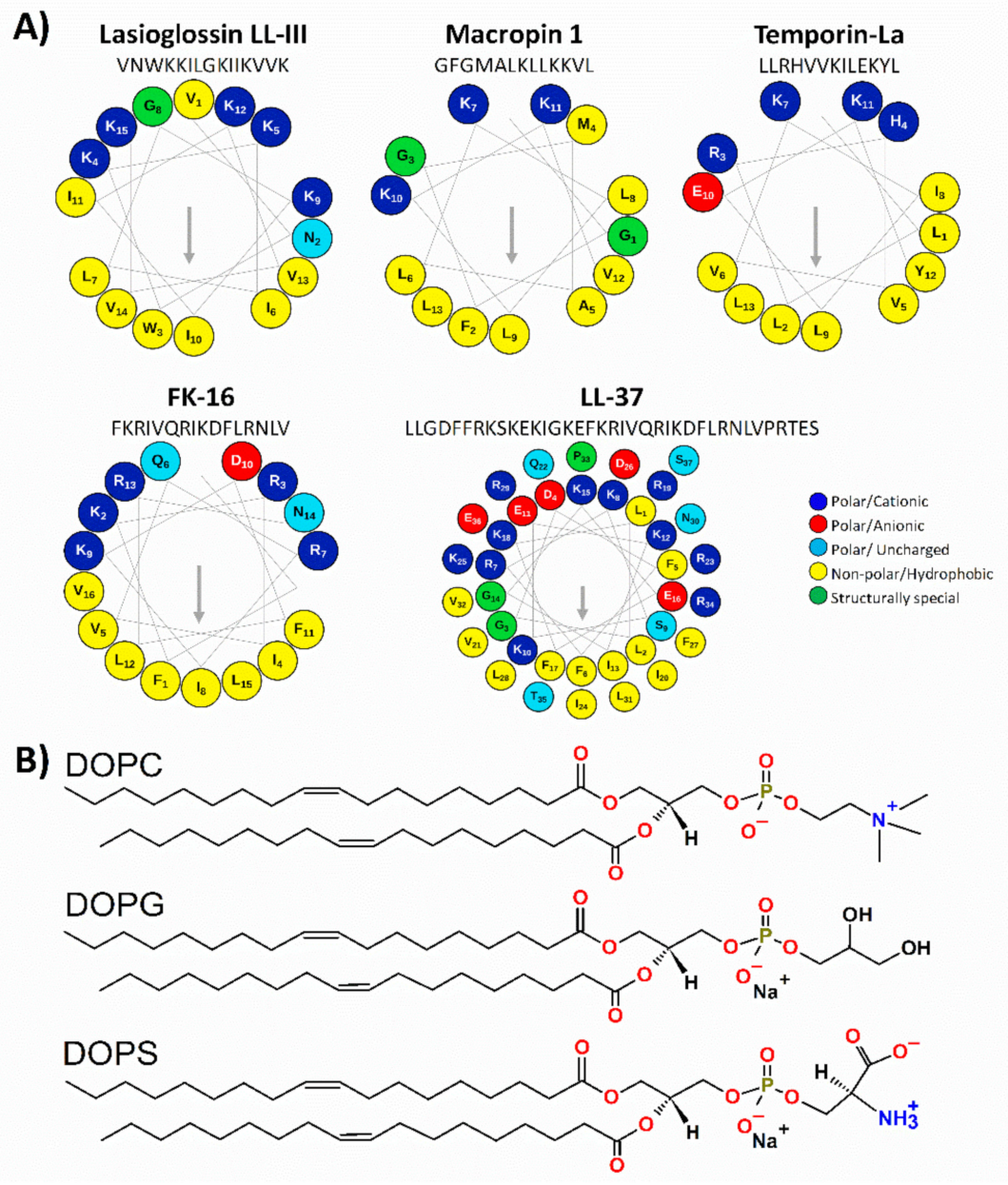

Scheme 1. Chemical structures of the compounds used in the study. (A) Helical wheel diagram of the peptides was drawn with the software package Protein ORIGAMI [62]. The arrow indicates the 
hydrophobic face of the peptide. (B) model membranes built up of phosphatidylcholine (DOPC, PC), phosphatidylglycerol (DOPG, PG), and phosphatidylserine (DOPS, PS) were used throughout the study. Pure PC, PC/PS (80:20), and PC/PG (80:20) were used for mimicking spatial distribution of electrostatic features for neutral and negatively charged biomembranes, respectively. Note the zwitterionic but net neutral nature of PC, the single negative charge of PG, and the $-/+/-$ charge distribution in the head-group of PS.

\section{Results}

\subsection{Peptide Structural Changes in the Presence of Lipid Membranes}

Conformational variations were assessed first by means of CD spectroscopy, collecting spectra in the far-UV region with PBS buffer. The free peptides exhibited a single negative band centred at around 197-200 nm with no significant shoulder in the 210-230 nm region (Figure 1A-D), in accordance with their intrinsically disordered state. In the case of LL-37, the CD spectrum was recorded in low ionic strength Tris buffer with no added salt, as inorganic anions induce the $\alpha$-helical conformation of the peptide (Figure 1E) $[30,63,64]$. The structural order of the studied ACPs was tested upon interaction with pure PC, PC/PG, and PC/PS liposomes, mimicking spatial distribution of electrostatic features for neutral and negatively charged biomembranes, respectively. Note that while other lipid components could also be considered here, that would, nevertheless, limit consistent comparisons with previous related results. Furthermore, some of the components, such as cholesterol, may have a marked effect on ACP behaviour; however, its content can drastically vary between different membranes or could even be missing, e.g., from bacterial bilayers. Thus, this consideration justifies the current choice of lipids and makes feasible the relative comparison of ACP properties as follows. In the presence of PC liposomes, the interaction with the lipid bilayer provoked the main negative band of the peptides to be redshifted to 203-208 $\mathrm{nm}$ together with a positive band developing in the short-wavelength region at around 193-195 $\mathrm{nm}$ and a negative shoulder at 221-223 nm (Figure 1A-E). This is in line with partial helical conversion $[65,66]$, which is observed most markedly for Tempo-La and FK-16 (Figure 1C,D). With PC/PG and PC/PS liposomes, all five peptides folded into a definite helical conformation (Figure 1A-E), where the spectral variations indicate longer, more regular helices in comparison with PC. This was also supported by the calculated helix content (Figure 1F, Insets Figure 1A-E). In general, the peptides showed a clear preference towards the negatively charged liposomes, particularly Tempo-La, FK-16 and LL-37. For Lasio III, Macro1, and Tempo-La, a somewhat higher helix content was estimated with the PC/PG liposomes ( 40-50\%) relative to the PC/PS liposomes ( 30-40\%). In contrast, the gain in helicity for FK-16 was highest with the PC/PS liposome ( 60\%), while the helicity was calculated to be the same $(\sim 43 \%)$ with PC and PC/PG. In the case of LL-37, the helix content was found to be the same ( $40 \%)$ with the negatively charged bilayers. It is to be noted that the fragment FK-16 behaved differently compared to its parent LL-37, as FK-16 folded into a highly helical conformation with all model membranes used. Besides, out of the five peptides studied, Lasio III showed the lowest helicity content in the presence of liposomes for all lipid compositions studied. The conformational effect of the lipid bilayers on the peptides was also assessed by IR spectroscopy, revealing peculiar variations in dry film samples (Figure S1 and related text). 

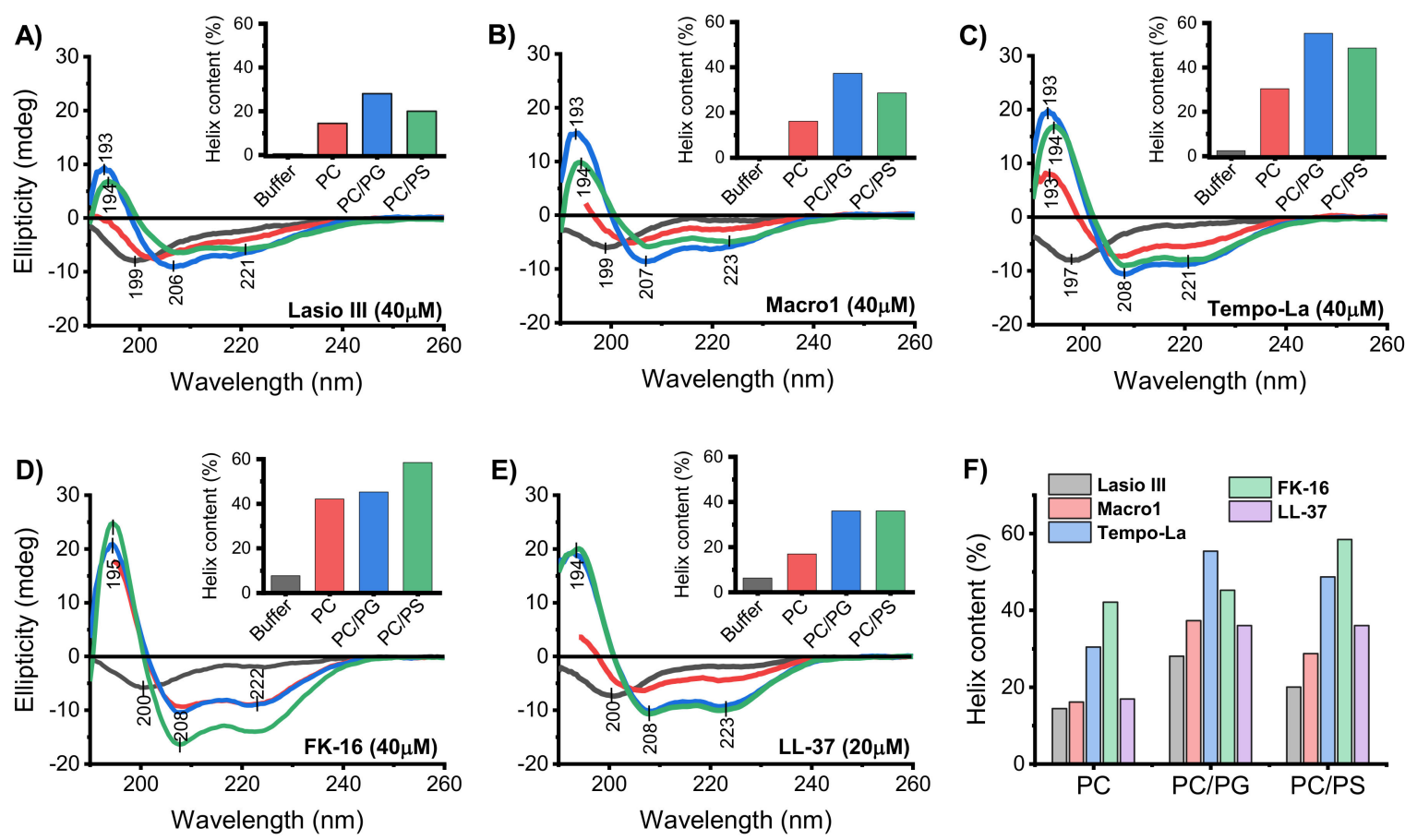

Figure 1. Peptide structural changes induced upon binding to model membranes assessed by CD spectroscopy. (A-E) Far-UV CD spectra in the presence and absence of the model membranes PC, PC/PG, and PC/PS. Spectra were collected at $635 \mu \mathrm{M}$ for (A-D) and at $320 \mu \mathrm{M}$ for (E) lipid concentration resulting in the same peptide-to-lipid ratio of 1:16. Insets show the calculated helix content. (F) Calculated peptide helix content with various lipid membranes. Helix content was calculated using the online tool (http:/ / bestsel.elte.hu) [67].

\subsection{Position and Binding Depth of the Peptides in the Membrane/Interaction of the Peptides with Lipid Groups in the Membrane}

IR spectroscopy can be used to explore the conformational effect of the lipid bilayers on the peptides; nevertheless, this technique also allows one to monitor peptide-membrane interactions by focusing on the changes in the properties of the lipids [68-71]. The analysis of the spectral regions characteristic of phospholipid vibrations revealed alterations in the polar head-group moiety $\left(\sim 1200-950 \mathrm{~cm}^{-1}\right.$, Figure $\left.2 \mathrm{~A}-\mathrm{C}\right)$, the lipid ester neck $\left(\sim 1735 \mathrm{~cm}^{-1}\right.$, Figure S1), and perturbations in the lipid order $\left(2850 \mathrm{~cm}^{-1}\right.$, Figure 2D-F).

The phosphate vibrations of zwitterionic PC liposomes were particularly perturbed by Macro1 and Tempo-La, which induced a shift of the $v_{\text {asym }} \mathrm{PO}_{2^{-}}$(Figure 2A). Moreover, increasing the intensity of the $v_{\mathrm{sym}} \mathrm{PO}_{2^{-}}$at $\sim 1060 \mathrm{~cm}^{-1}$ compared to the lipid alone (Figure 2A) for the peptides Lasio III, Macro1 and Tempo-La suggested an interaction with the phosphate groups and an impairment of the lipid head-group packing [72,73]. Regarding the anionic PC/PG liposome (Figure 2B), analogously to PC membranes, Lasio III, Macro1 and Tempo-La induced a similar shift in the $v_{\text {asym }} \mathrm{PO}_{2^{-}}$and an increased intensity in the $v_{\text {sym }} \mathrm{PO}_{2^{-}}$, whereas a modest shift of $v_{\text {asym }} \mathrm{PO}_{2^{-}}$was induced by LL-37 and FK-16. A peculiar perturbation of $v_{\mathrm{sym}} \mathrm{PO}_{2^{-}}$and choline stretching at $\sim 970 \mathrm{~cm}^{-1}$ can be observed only in the case of the 37-mer peptide (Figure 2B). For PC/PS liposomes, a significant effect was revealed with Lasio III and LL-37, which caused alteration of the $v_{\text {asym }} \mathrm{PO}_{2^{-}}$and choline stretching vibrations (Figure 2C). 

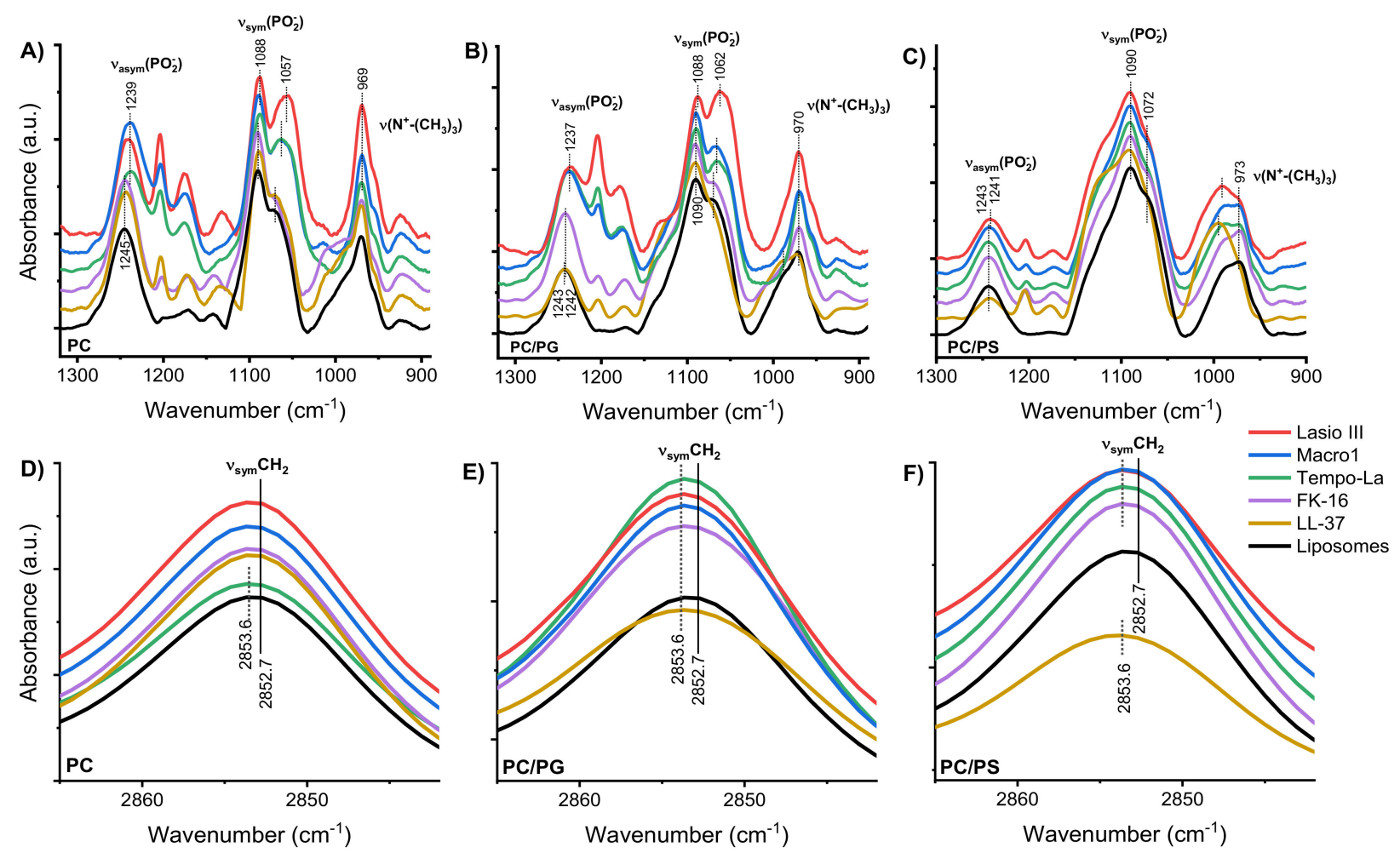

Figure 2. Membrane interaction studied by infrared spectroscopy (IR). Representative infrared spectra in the lipid headgroup region of (A) PC, (B) PC/PG, and (C) PC/PS membranes alone and upon interaction with the studied peptides. The analysed vibrational modes, namely $v_{\text {asym }}\left(\mathrm{PO}_{2^{-}}\right), v_{\mathrm{sym}}\left(\mathrm{PO}_{2^{-}}\right)$, and $v\left(\mathrm{~N}^{+}-\left(\mathrm{CH}_{3}\right)_{3}\right)$, refers to the asymmetric and symmetric phosphate stretching, and to the asymmetric choline stretching, respectively. Representative infrared spectra of the acyl $\mathrm{CH}_{2}$ group region of (D) PC, (E) PC/PG, and (F) PC/PS membranes alone and upon interaction with the studied peptides. Peptide and lipid concentrations were $80 \mu \mathrm{M}$ and $1.27 \mathrm{mM}$, respectively, for all the peptides except for LL-37 which was $40 \mu \mathrm{M}$ and $0.635 \mathrm{mM}$, respectively, resulting in the same peptide-to-lipid ratio.

For the ester $\mathrm{C}=\mathrm{O}$ stretching vibration (Figure S1B-D), a shift from 1737 to $1735 \mathrm{~cm}^{-1}$ in the presence of the peptides Lasio III and Tempo-La was detected with PC liposomes (Figure S1B), which is indicative of peptide binding down to the lipid neck region. In the case of anionic PC/PG and PC/PS liposomes (Figure S1C,D), a shift (from 1736 to $1737 \mathrm{~cm}^{-1}$ ) was detected for mostly all the studied peptides, especially for Lasio III and LL-37, which suggests structural arrangement/alterations in the polarity and/or hydration of the polar-apolar interfacial region of the lipid bilayer upon interaction with the ACPs.

Lastly, the symmetric stretching vibration of the methylene groups, $v_{\mathrm{sym}} \mathrm{CH}_{2}$ at $\sim 2850 \mathrm{~cm}^{-1}$, could be used for semi-quantitative characterization of concomitant changes in hydrocarbon chain conformational disorder [74,75]. In comparison with the pure lipid systems, for PC liposome, small shifts to higher wavenumbers and broadening can be detected upon addition of Tempo-La (Figure 2D). More pronounced shifts and peak broadening were detected with the negatively charged liposomes for the studied peptides (Figure 2E,F). The most remarkable changes were induced by LL-37, particularly with PC/PS, where a shift from $2852.7 \mathrm{~cm}^{-1}$ to $2853.6 \mathrm{~cm}^{-1}$ indicated more disordered acyl chain packing upon peptide binding (Figure 2F) [76].

\subsection{Orientation of the Peptides in the Membrane}

Linear dichroism (LD) spectroscopy was used to study the orientation and alignment (binding geometry) of the peptides bound to lipid bilayers. Linear dichroism gives information on the orientation of chromophores in a macroscopically aligned system as it measures the differential absorption of linearly polarized light parallel and perpendicular to an orientation axis $[66,77]$. Liposomes can be deformed by shear flow in a rotation 
Couette cell, resulting in slightly ellipsoidal vesicles which align in the flow [78]. Thus, the sign and magnitude of each peptide absorption band in the LD spectrum reports on the orientation of the corresponding transition moment relative to the membrane [78-80].

In the presence of model membranes, all five peptides displayed a positive peak at $\sim 210 \mathrm{~nm}$ (Figure 3A,B and Figure S2), which corresponds to the low-energy component of the peptide bond $\pi \rightarrow \pi^{*}$ transition moment along the helix axis (Figure 3C) [78,81-83]. Thus, the positive sign of this peak suggests that the helical part of the peptide lies parallel to the surface of the membrane. Exceptionally, the Tempo-La helix seems to align perpendicular to the surface on negatively charged vesicles, as indicated by the small negative peak at $\sim 215 \mathrm{~nm}$, probably shifted from $\sim 210 \mathrm{~nm}$, between two large positive signals (Figure 3B). The LD signal intensity in the 210-250 $\mathrm{nm}$ region followed the order LL-37, FK-16 > Tempo-La > Lasio III > Macro1, which could be correlated with the helix content detected by CD above. Furthermore, the reduced LD signal of all absorption bands in this region in the presence of neutral lipid bilayers might indicate a decreased overall alignment due to the less disruptive effects of the peptides on the lipid order [79]. The $n \rightarrow \pi^{*}$ transition in an $\alpha$-helical conformation is perpendicular to the helix axis and appears at $\sim 210-230 \mathrm{~nm}$ in the LD spectrum [84] (Figure 3C). This infers that the sign of the LD peaks at $\sim 210 \mathrm{~nm}$ and at $\sim 220-230 \mathrm{~nm}$ should be opposite since the corresponding transitions are orthogonal. In line with this, the peptides with a positive LD at $\sim 210 \mathrm{~nm}$ exhibited negative peaks at $220-230 \mathrm{~nm}$ (Figure 3A and Figure S2A-C), further supporting a helical state, aligned parallel to the membrane plane, except for the peptide Tempo-La as mentioned before (Figure 3B). In the case of Lasio III and Tempo-La, however, the band at 220-230 nm cannot be assigned solely to the amide $n \rightarrow \pi^{*}$ transition since the aromatic residues, Trp in Lasio III and Tyr in Tempo-La, also absorb in this region. Thus, these peptides were analysed in more detail, also utilizing other methods reporting sensitively on these side chains.

In the case of Lasio III, the LD peaks corresponding to the transition moments of the indole ring moiety (Figure 3A, inset) can be analysed. The intense negative LD peak at $228 \mathrm{~nm}$ suggests that the tryptophan $B_{b}$ transition moment is oriented essentially perpendicular to the membrane surface (Figure 3A). Conversely, both the broad and unstructured $L_{a}$ band at $\sim 250-270 \mathrm{~nm}$ and the vibrational structured $L_{b}$ band at $\sim 290 \mathrm{~nm}$ display positive LD signals (Figure $3 \mathrm{~A}$ ), which are indicative of an orientation parallel to the membrane surface $[81,85]$. All of these point to a tryptophan interplay at the membrane interface where the most hydrophobic part of the side-chain is oriented towards the membrane interior, while the electronegative nitrogen is towards the polar lipid head-groups [79]. This was further supported by intrinsic peptide fluorescence where, upon membrane binding, the Trp emission maximum blue-shifted from $348 \mathrm{~nm}$ to $325 \mathrm{~nm}$ (Figure 3D), which is characteristic for a Trp residing in a rather apolar microenvironment [86,87]. Thereby, the effect presumably includes the incorporation of the side chain into the membrane, which was more pronounced with the negatively charged liposomes. The combined LD and fluorescence data suggest that while the helical peptide lies parallel to the surface of the membrane, the Trp residue points away from the helix axis towards the hydrophobic membrane interior. In contrast, for the PC-bound peptide, the rather wide fluorescence emission peak, with only a slightly blue-shifted maximum compared to the free peptide, might indicate tryptophan populations in solvent-exposed environments [88]. 

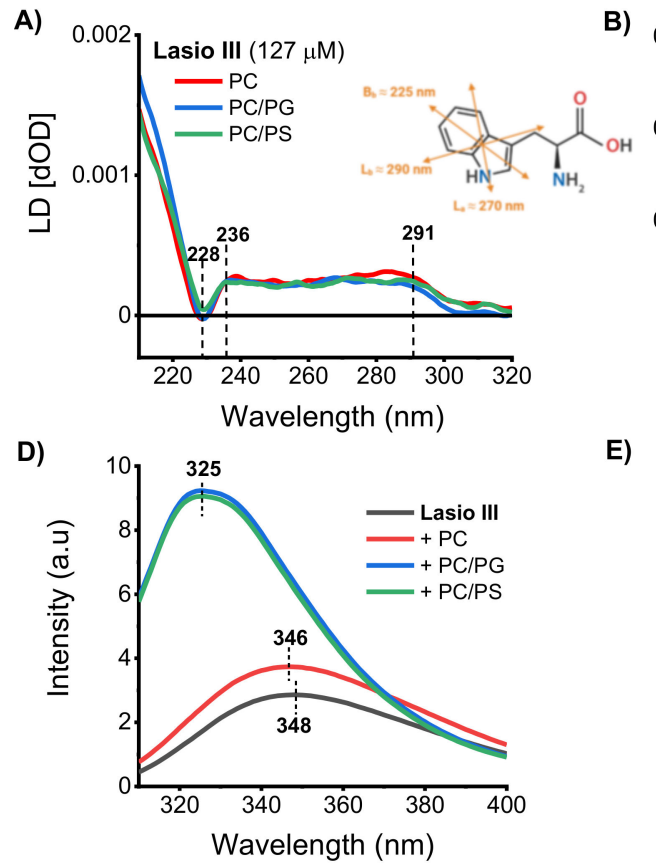

B)

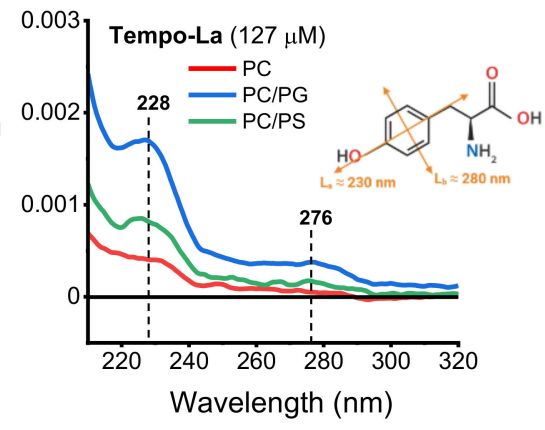

E)

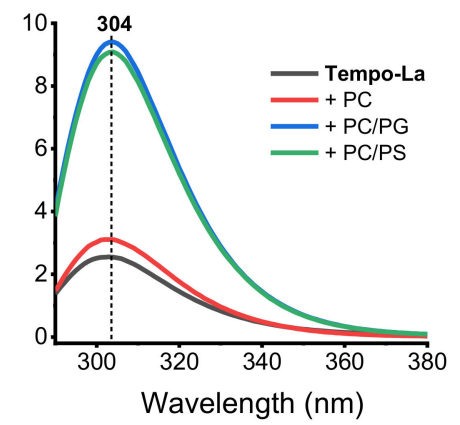

C)
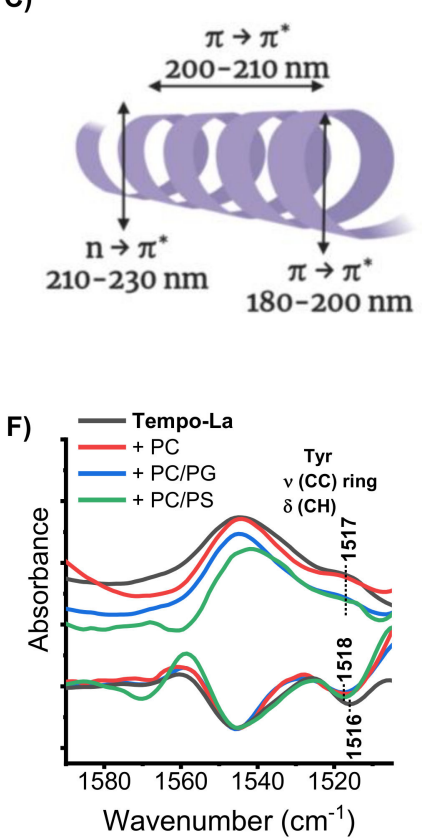

Figure 3. Peptide orientation upon binding to lipid membrane. (A,B) LD spectra of Lasio III (A) and Tempo-La (B) in the presence of the model membranes PC, PC/PG, and PC/PS. Spectra were collected at $1.27 \mathrm{mM}$ lipid concentration. (C) Schematic representation of the transitions moment directions of an $\alpha$-helical peptide secondary structure. (D,E) Fluorescence emission spectra of Lasio III (Trp fluorophore, excited at $295 \mathrm{~nm}$ ) (D) and Tempo-La (Tyr fluorophore, excited at $275 \mathrm{~nm})(\mathrm{E})$ in the presence and absence of model membranes. Peptide and lipid concentrations were 2 and $100 \mu \mathrm{M}$, respectively. (F) IR analysis of the tyrosine band of Tempo-La alone and in the presence of lipid membranes, showing the Tyr vibration band region. Second derivative is shown below and was used for peak identification. Peptide and lipid concentrations were $80 \mu \mathrm{M}$ and $1.27 \mathrm{mM}$, respectively.

Tempo-La contains a single Tyr residue where the side-chain phenol group possesses two orthogonal in-plane transition moments (Figure 3B, inset). The absorbance peaks at $\sim 230 \mathrm{~nm}$ ( $L_{a}$ band) and at $\sim 280 \mathrm{~nm}$ ( $L_{b}$ band) correspond to the transition moments polarized along the long and the short axis of the phenol ring, respectively. The positive LD signal was detected at $228 \mathrm{~nm}$, which also corresponds to the $L_{a}$ band, indicating that the chromophore might lie parallel to the membrane surface. Therefore, special focus should be put in the near UV region where only the aromatic residues contribute; a positive LD signal was clearly detected for the $L_{b}$ band at $276 \mathrm{~nm}$ (Figure 3B), which is indicative of a chromophore lying parallel to the membrane surface $[78,80]$. According to signal intensities, the phenol ring has the most defined positioning with PC/PS. Based on LD spectral features considering helix orientations detailed above, it is possible to hypothesize a unique binding mode for Tempo-La where the helical part is rather parallel with the membrane normal with $\mathrm{PC} / \mathrm{PG}$, while rather parallel with the membrane plane with PC, and can bobble between these two orientations with PC/PS. This idea is supported by simulation results (see below, Figure 6B,C) showing an "antenna-like" binding mode upon binding to PC/PS where the C-terminal helical part can freely move around the $\mathrm{N}$-terminal anchoring segment. In addition, intrinsic peptide fluorescence data utilizing Tyr fluorescence (Figure 3E) provided further details. In the presence of PC/PG and PC/PS vesicles, an increase in emission intensity was detected compared to the non-bound peptide. This implies that the fluorescence of the peptide is quenched in the absence of lipids, presumably due to the proximity of Tyr residues in a self-assembled state. Indeed, we could detect peptide associates by DLS (Figure S3A). However, interaction with lipids forces the peptides to dissociate and bind separately to the vesicles. Interaction of the Tyr group with the vesicles was further indicated by IR data based on shifts of the Tyr 
$v(C C)$ ring vibration band from $1516 \mathrm{~cm}^{-1}$ of the free peptide to $1518 \mathrm{~cm}^{-1}$ observed in the presence of the liposomes (Figure 3F).

\subsection{Effect of the Peptides on the Size and Morphology of Model Vesicles}

From the molecular level effects of the ACPs on the lipid bilayers above, we also examined macroscopic effects, thus testing changes of vesicles in size and morphology. DLS data indicated that peptide binding hardly affected liposome integrity to a detectable level. No significant changes were detected for PC and PC/PG liposomes (Figure S3B,C), and only Lasio III and Macro1 induced shifts of the correlation function with PC/PS liposomes (Figure 4A). The latter is indicative of an emerging vesicle subpopulation of $\sim 150 \mathrm{~nm}$ compared to the $100 \mathrm{~nm}$-sized intact vesicles, where the liposomes were presumably bridged by the peptides. Although no vesicle aggregation was detected for LL-37 using DLS, FF-TEM images clearly demonstrated such an effect with PC/PS liposomes. The pure lipid system was characterized by isolated, spherical-shaped, $100 \mathrm{~nm}$-sized, unilamellar vesicles (Figure $4 \mathrm{~B}$ ), while the interaction with LL-37 promoted the contacts between the lipid vesicles, leading to a "shell-packed" morphology (Figure 4C) with a group of nearby vesicles enclosed in a shell-like envelope. Previous investigations on the cationic peptide DHVAR4 with anionic membranes showed similar behaviour, where small groups of closely located vesicles were embedded into larger shell-like structures [89].

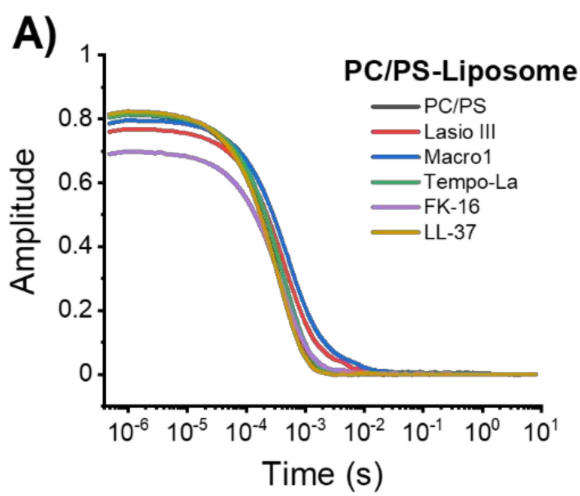

B)

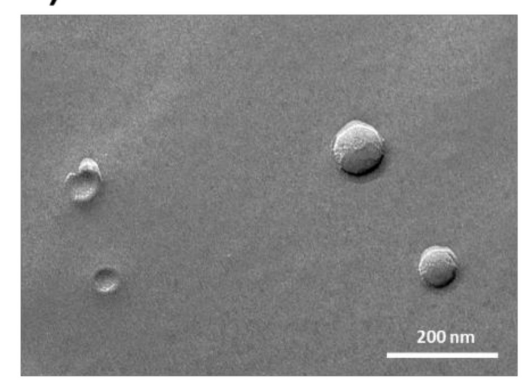

C)

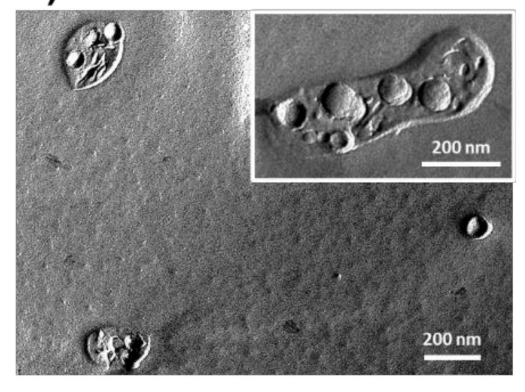

Figure 4. Size and morphology variations of the vesicles induced by the ACPs. (A) Correlation function by DLS for the studied ACPs in the presence of the lipid membrane PC/PS; peptide and lipid concentrations are 40 and $635 \mu \mathrm{M}$ for all the peptides, except for LL-37, which is 20 and $320 \mu \mathrm{M}$, respectively. Freeze fractured TEM images of (B) PC/PS-alone; lipid concentration $2540 \mu \mathrm{M}$ and (C) LL-37-PC/PS mixture; peptide and lipid concentration are 80 and $2540 \mu \mathrm{M}$, respectively.

\subsection{Molecular Dynamics Simulations on the Peptide-Lipid Interactions}

To further address peptide-lipid interactions on the molecular level, molecular dynamics (MD) simulations were also carried out. Peptides were placed approximately three nanometres away from the surface of the model membrane (PC, PC/PG, or PC/PS) and simulated for 500 nanoseconds. Based on the $\mathrm{CD}$ results above, the initial secondary structure was chosen to be helical.

First, the helicity was monitored over the simulation time (Figure 5A-C and Figure S4), which provides an indirect way to study bilayer-induced conformational changes without tedious rare event sampling methods. The helix content of the peptides showed remarkable differences with respect to the applied model membrane. Lasio III exhibited the most peculiar behaviour. Its secondary structure remained mostly helical in the presence of the PC/PS membrane, and it still retained some helicity with the PC bilayer; in contrast, helicity was lost with the PC/PG bilayer (Figure 5B). It should also be noted that Lasio III was the only peptide for which the presence of the PC/PG bilayer hampered peptide helicity instead of promoting it. Although this is somewhat contradictory to CD results, where some helical conversion was observed with the PC/PG liposome, however, the helix content was the lowest for this peptide. On the other hand, Macro1 remained helical only 
in the presence of the PC/PG bilayer and lost helicity with the PC and PC/PS bilayer (Figure 5A,C). Tempo-La and FK-16 retained most of their helicity for the entire course of the simulation, irrespectively of the model membrane (Figure 5A-C). Finally, LL-37 retained some helix content with the PC liposome, but higher helicity is observed with PC/PG and PC/PS membranes (Figure 5B,C).

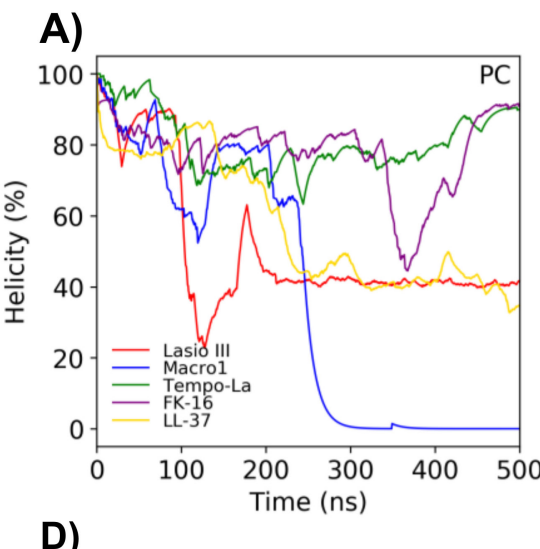

B)

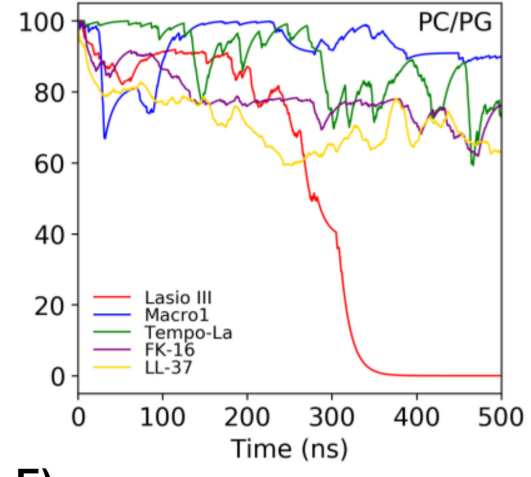

E)
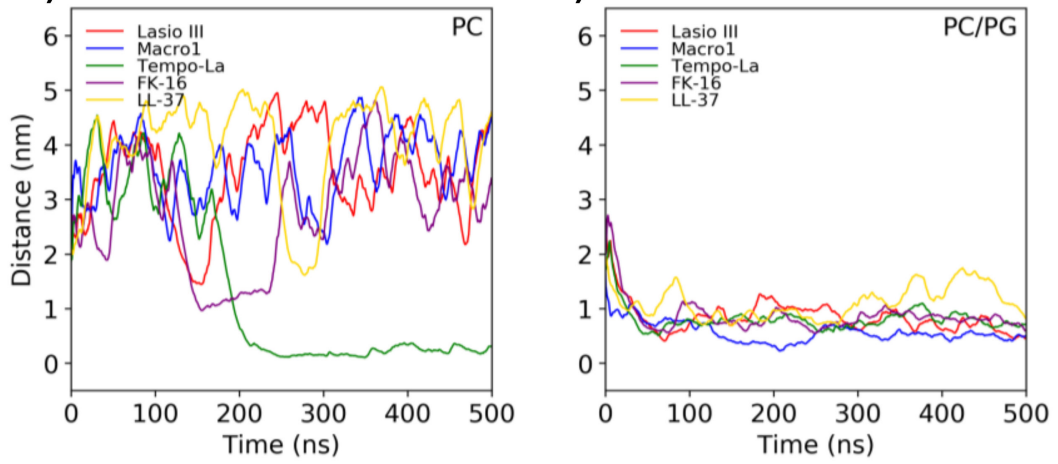

C)

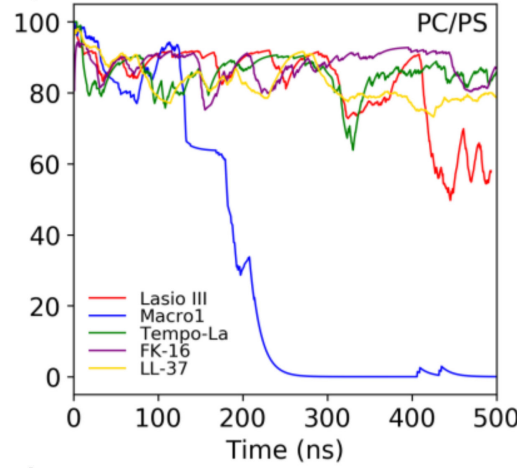

F)

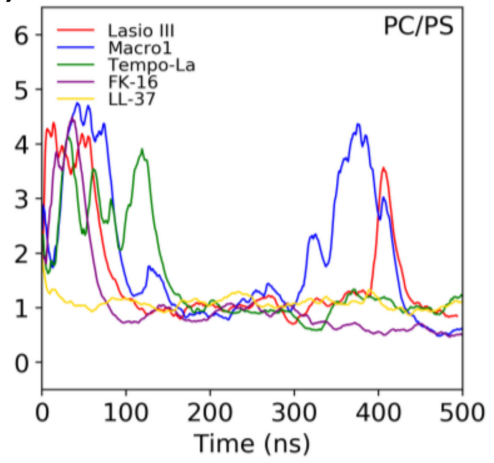

Figure 5. Peptide helicity changes in the presence of model membranes and distance of the ACPs from the bilayer during the MD simulations. The helicity of the peptides in the presence of the model membranes (A) PC, (B) PC/PG and (C) PC/PS is defined as the number of the residues with $\alpha$-helical structure divided by the total number of the residues minus the two terminal residues (for further information see the methods section). The distance of the peptides from the surface of the different model membranes (D) PC, (E) PC/PG and (F) PC/PS as a function of the simulation time.

Moreover, peptide distance from the bilayer surface was also calculated as a function of the simulation time (Figure 5D-F and Figure S5). Interestingly, none of the peptides were found close to the PC bilayer, except for Tempo-La at $>200 \mathrm{~ns}$ (Figure 5D), which is in line with the LD results suggesting that Tempo-La resides parallel to the membrane surface of PC. On the other hand, the most straightforward interpretation comes with the PC/PG membrane because all the studied peptides bound almost immediately and irreversibly onto the bilayer surface as indicated by the small peptide-surface distances (Figure 5E). Likewise, this behaviour remained characteristic for the PC/PS bilayer as well; however, peptide binding was less immediate and irreversible, especially for Lasio III and Macro1 (Figure 5F).

The combined results from MD simulations revealed several details regarding the peculiar binding mode of the studied ACPs. A unique behaviour was detected for Lasio III that lost its helicity upon binding to the PC/PG surface, oppositely to all the other peptides studied here, which indicates a potentially different mechanism for this peptide, as it was able to bind to the other negatively charged liposome PC/PS (Figure 6A). It was also observed that, as indicated by LD, the Trp of Lasio III is oriented towards the inside of the bilayer (Figure 6A). Furthermore, Tempo-La was able to bind even to the zwitterionic PC membrane (Figure 6B) and inserted the deepest among all the other peptides, which is 
potentially the reason for its higher helicity. Moreover, a unique orientation can be observed for this peptide with PC/PS; namely, it is attached to the membrane surface, but its helix is oriented perpendicular to the membrane surface (Figure 6C), as also suggested by LD data. In the case of the cathelicidin peptide and its fragment, the interaction of LL-37 fits the general picture obtained experimentally, as it selectively binds to negatively charged PC/PG and PC/PS (Figure 6D), where it shows pronounced helicity. FK-16 retained its helicity in the presence of all model membranes studied, even though it did not bind to the surface of the PC bilayer, which indicates its high affinity for a helical structure.
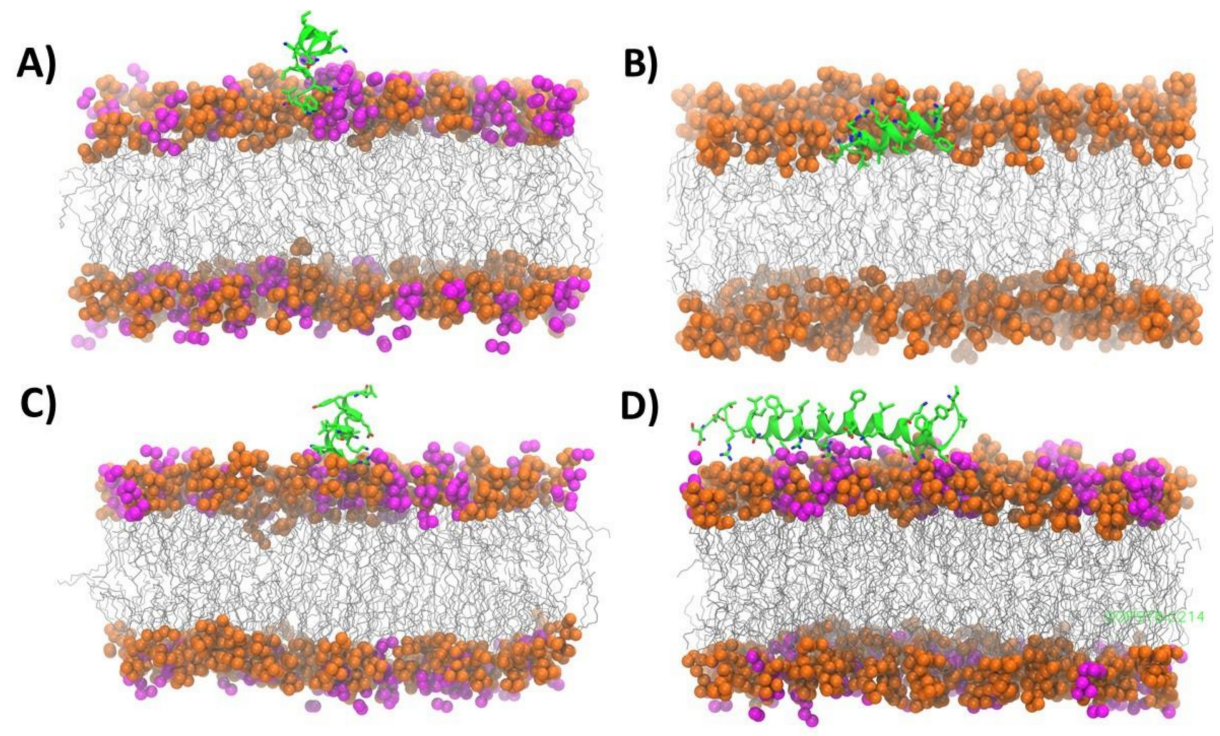

Figure 6. Membrane orientation of selected ACPs in the MD simulations. (A) Lasio III in the presence of PC/PS bilayer. (B,C) Tempo-La in the presence of PC and PC/PS bilayer, respectively. (D) LL-37 in the presence of PC/PS bilayer. The backbone of the peptides is shown as green cartoon. The lipid head groups are represented by orange (PC) and magenta (PS) spheres, while the lipid alkyl chains are grey lines. The $\mathrm{H}$-atoms are not shown for better clarity. Representative snapshots were taken at the end of the simulations (at $500 \mathrm{~ns}$ ).

\subsection{Interaction of ACPs in a More Complex Membrane System}

To better understand the effect of the investigated ACPs on biomembranes, a more complex membrane system was also applied. Previous studies have suggested that red blood-cell derived extracellular vesicles (REVs) can be used as improved model systems to study membrane interactions, as they can be produced on a large scale, are non-toxic, and have a monodispersed size distribution making them suitable for biophysical experiments $[90,91]$. We have demonstrated that membrane-active peptides target not only the lipid bilayer of extracellular vesicles but also that their unique action can result in the removal of EV-associated protein corona members [92]. To improve our mechanistic understanding, LL-37, FK-16, and Tempo-La were selected, and their interactions with REVs were studied by increasing ACP concentration and monitoring with LD spectroscopy.

The LD spectrum of free REVs (Figure 7A-C) displays a major positive band at $\sim 220 \mathrm{~nm}$ arising from a mixture of the $n \rightarrow \pi^{*}$ and $\pi \rightarrow \pi^{*}$ amide transition of REV proteins and a peak with a lower intensity at $\sim 420 \mathrm{~nm}$ corresponding to the Soret band of heme proteins, which, in the case of REVs is haemoglobin [84,93]. Titration of REVs with ACPs resulted in a substantial decrease of both LD bands at $220 \mathrm{~nm}$ and $420 \mathrm{~nm}$, showing the most abrupt change for the peptide LL-37 (Figure 7A). At a concentration of $5 \mu \mathrm{M}$, LL-37 has already reduced both main absorption bands by $\sim 50 \%$ compared to the control REVs, and its further addition up to $40 \mu \mathrm{M}$ led to complete loss of the LD signal (Figure 7D). A similar trend was observed for FK-16, though higher peptide concentrations were needed to reach the same intensity decrease (Figure 7B,D). In contrast, no significant 
change was observed for Tempo-La at $40 \mu \mathrm{M}$, and $\sim 25 \%$ of the haemoglobin peak was still detected at $200 \mu \mathrm{M}$ (Figure 7C,D). These results indicate that the ACPs applied here could affect REV associated proteins, even when the effective concentration seems to depend on the peculiar peptide.
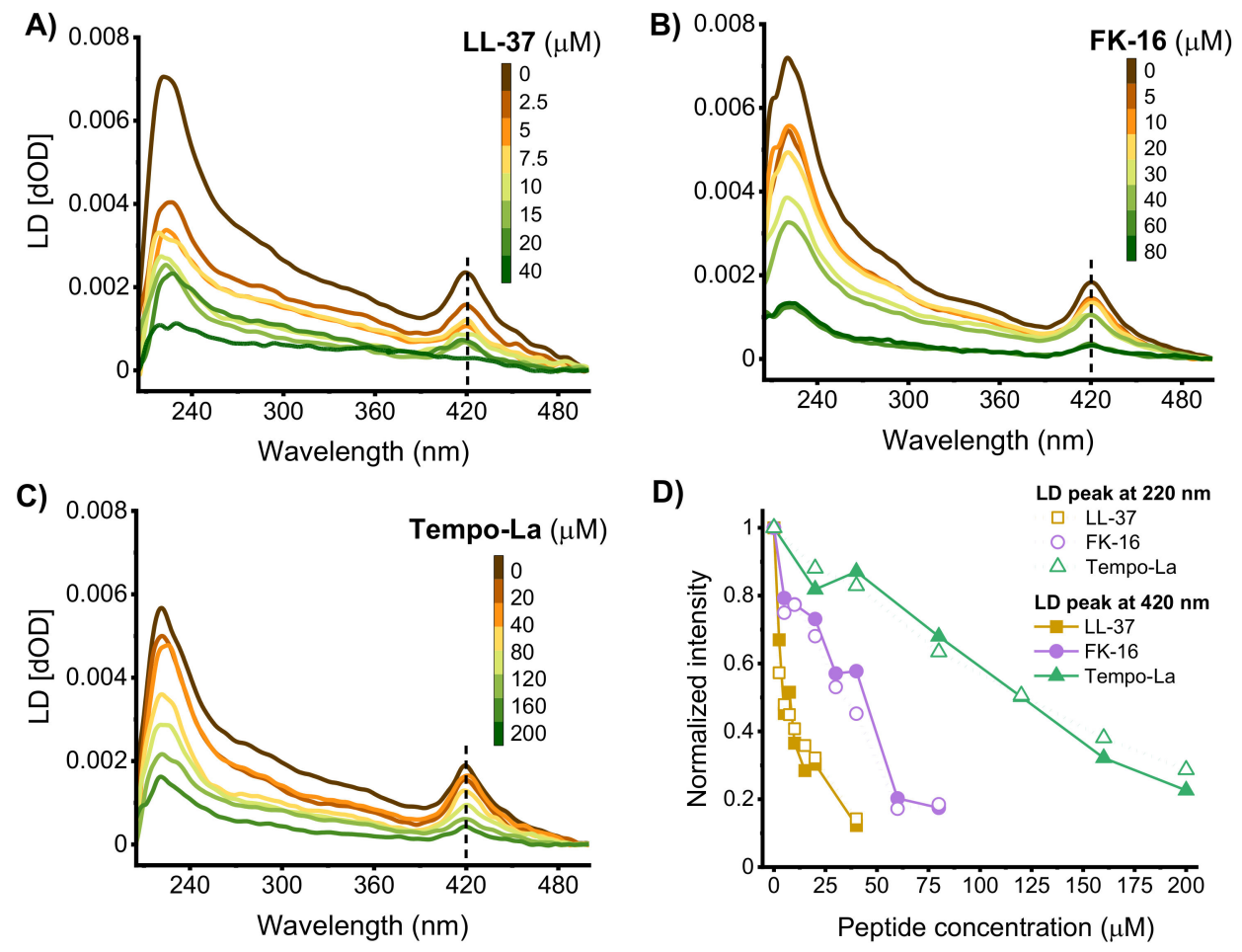

Figure 7. REV-ACP interactions studied by LD spectroscopy. The Soret band in the LD spectra of REVs is indicative on how ACPs interact with the surface of the vesicular bilayer. LD spectra of REVs upon addition of (A) LL-37, (B) FK-16, and (C) Tempo-La. (D) LD peak intensity at $420 \mathrm{~nm}$ (close symbols) and at 220 (open symbols) as a function of the ACPs. Data are normalized to values measured in the absence of peptides.

Structural effects upon REV-ACP interactions were also followed by CD and IR spectroscopy. Very similar spectral changes were detected here (Figure S6 and related text in SI) as observed previously on melittin and CM15 [92], which is indicative of a common action exerted by this set of peptides. All these findings suggest that the novel function, e.g., the removal of REV-associated proteins revealed for melittin and its hybrid CM15, can be extended to several cationic membrane-active peptides. However, the ACPs applied here could affect REV associated proteins to a different extent, presumably depending on their type of interaction mechanism.

\section{Discussion}

In the activity of membrane-active peptides, selectivity towards a particular membrane composition is a key factor. We found that the five studied ACPs clearly differ in their lipid preference. Overall, the peptides showed preferred binding to PC/PG and PC/PS over pure PC liposomes. Particularly, moderate helical folding was observed for Lasio III, Macro1, and LL-37 in CD experiments. Reduced helicity was supported by MD simulations, in which these three peptides lose helicity by the end of the employed simulation time (Figure 5A). This behaviour is in line with the well-known fact that positively charged peptides often show lower affinity towards neutral, zwitterionic phospholipids [94], from which the outer leaflet of the mammalian cell membrane is exclusively composed [95,96]. In contrast, Tempo-La and FK-16 showed high helicity even in the presence of PC liposomes, as indicated by both $\mathrm{CD}$ and $\mathrm{MD}$ results (Figures $1 \mathrm{~F}$ and $5 \mathrm{~A}$ ). These suggest that for 
the latter two ACPs, electrostatic interactions with the polar groups of the lipids could be stronger. Among the negatively charged vesicles, Lasio III, Macro1 and Tempo-La preferred PC/PG liposomes while FK-16 preferred PC/PS liposomes. In contrast, LL-37 displayed a preference towards neither PG nor PS liposomes (Figure 1F). These findings show that their membrane interaction depends not only on simple electrostatics but the spatial distribution of the charged moieties within the lipid headgroup and along the peptide sequence can fine-tune their binding. As cancer cells are characterized by exposed PS, peptide preference for PS argues for good anticancer activity. Indeed, FK-16 is known for its excellent anticancer efficiency $[35,36]$. However, FK-16 showed comparable folding in the presence of PC and PC/PG liposomes, which might be attributed to its high helix propensity. The latter is supported by the helical wheel projection showing an amphipathic helix with perfect separation of the hydrophilic and hydrophobic residues (Scheme 1A). Thus, the high intrinsic helicity of the peptide promotes interaction and helical folding even with PC bilayers. For its parent peptide, LL-37, some hydrophobic residues insert in the hydrophilic side. Moreover, several negatively charged residues and helix breaker residues are present, which can lead to a loosening of the helical conformation and, in turn, to enhanced selectivity towards negatively charged membrane surfaces, as observed here. Out of the studied peptides, Lasio III showed the lowest helix content (Figure 1F) for all three model membranes used. The experimental observation is in full line with the qualitative results of the MD simulations, as this peptide was shown to lose helicity during the simulations (Figure 5A-C).

To better understand the relationship between sequence and mode of membrane association, it is also important to consider that the studied ACPs change their initial structure to optimize their interaction with membranes. This conformational change is proposed to increase the amphipathicity of the membrane-bound peptide [97]. The latter property is strongly related to their hydrophobicity and net charge, and this could affect peptide activity, target selectivity, and toxicity towards eukaryotic cells [9]. Based on the mean hydrophobicity $(\mathrm{H})$ of their sequence and the mean hydrophobic moment $\left(\mu_{H}\right)$, in their $\alpha$-helical form $[49,50,98]$, many of the studied ACPs have a strong tendency to reside on the surface of the membrane. FK-16 and Tempo-La are the two ACPs out of the five which have the highest helicity upon membrane association. Interestingly, based on the helical wheel model (Scheme 1A), and their $\mu_{H}$ and $\mathrm{H}$ values (Table 1), they are rather similar. However, current results demonstrate that these peptides are oriented preferentially perpendicular to each other on the membrane surface. A particular difference between the two peptides could be that for Tempo-La, the apolar residues are somewhat dominating ( 8 over 5), whereas, for FK-16, these are more evenly distributed (8 to 8). The MD simulations also show that for Tempo-La, its' LLR N-terminal motif has a high affinity to the lipid headgroup region, with the Arg side chain having multiple hydrogen bonds formed when coordinating on the phosphate and carboxyl groups of the PG and PS lipids. Due to the longer size of the Arg side chain, the simultaneous surface presence of Leu-Leu and the Arg side chain can only occur in case the latter acts as a support on the side of the formed highly helical secondary structure, which thus positions the helix upwards initially. This, combined with the fact that the sequence is rather short (only 13 residues; FK-16 has 16), and has only three cationic residues (FK-16 has 5), will thus, result in reduced electrostatic attraction towards the membrane surface. Furthermore, although both Lasio III and Macro1 have high $\mathrm{H}$ and $\mu_{H}$ values favouring helix formation, their lower helical character could be linked to Gly residues in their relatively short sequences (15 and 13 aa for Lasio III and Macro1, respectively). Gly tends to disrupt helices because its high conformational flexibility makes the formation of the constrained $\alpha$-helical structure entropically expensive. In the case of LL-37, some parts of the long sequence are expected to be very similar to FK-16, whereas other sequential regions, particularly with negatively charged residues, could have more distinct properties from common amphipathic ACPs and AMPs (Table 1).

Beyond the above observations and considerations on peptide helicity, it can already be seen for the case of Tempo-La that the combination of the employed experimental 
and computational techniques allowed further differentiation. In this respect, flow-LD spectroscopy and MD simulations prove to be particularly useful, as they provide structural information on the orientation of the helical ACPs relative to the membrane surface and fluorescence results and experiments with REV vesicles gave new insights on the surface affinity and association mode of the ACPs. Based on these, the five peptides investigated were categorized into three binding modes as follows (Scheme 2).
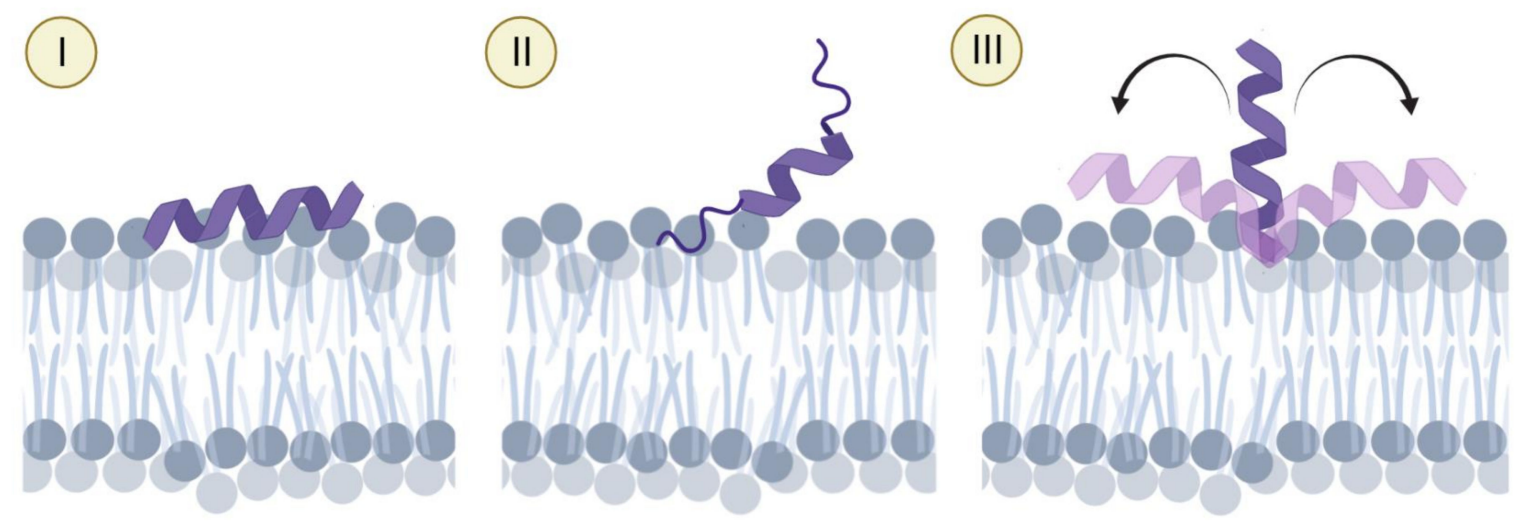

Scheme 2. Proposed membrane-association mechanism for the peptides used in the study. (I) Highly helical, occupying a higher space on the surface in line with the general carpet model observed for FK-16 and LL-37. (II) Partially helical, still mostly lying on the surface observed for Lasio III and Macro1. (III) Highly helical, but preferentially perpendicular to the surface, occupying smaller space identified for Tempo-La.

\subsection{Highly Helical—Carpet Model}

This binding mode is proposed for FK-16, and to some extent, its longer precursor peptide LL-37, where the highly helical ACPs associate to the membrane surface via interacting mainly with the headgroup region of the lipids (Scheme 2). The helical parts of these peptides seem to be oriented preferentially parallel to the membrane surface, as indicated by LD (Figure S2B,C) as well as by the MD simulations. The latter method confirmed both high helicity and close attachment to the membrane surface (Figure 5). IR analysis also showed that they perturb the phosphate and choline groups of the lipids (Figure 2), suggesting their binding to the surface of the bilayer. Distinctive perturbations were also found for the lipid ester and acyl chain vibrations, especially for LL-37 with PC/PS liposomes, showing a strong membrane interaction affecting deeper regions of the bilayer perturbing lipid order and packing as well. The results with REVs suggested that they could efficiently remove the surface-associated protein corona in a concentration-dependent manner, which promotes that their helices covering the vesicle occupy a relatively large space on the EV surface [92] (Figure 7D). In this case, the longer LL-37 was proven to be more effective. Thus, this highly helical conformation, with the helix being parallel to the membrane surface, represents a binding mode that is compatible with the carpet model described for AMPs $[15,99]$, in which the peptides accumulate on the surface of the target membrane.

\subsection{Partially Helical, Surface Binding}

The second proposed binding mode was found for Lasio III and Macro1, which is similar to the first one to some extent; however, here, only a partial folding of the peptide is achieved upon interaction with the membrane (Scheme 2). This is clearly supported by CD (Figure 1A,B) and by their low-intensity LD spectra (Figure 3A and Figure S2A). In line with experiments, MD simulations also qualitatively demonstrate the significant decrease in helicity during the time course of the simulation for all lipid compositions studied (Figure 5A-C and Figure 6A). This strongly suggests that despite markedly increased helicity in the presence of negatively charged liposomes, these peptides have a lower inherent propensity to fold into a regular helical structure compared to the peptides of the 
first binding mode. However, IR showed that the perturbed phosphate group vibrations were particularly noteworthy, as was the impact of Lasio III on the polar moiety of all the examined lipid systems. The latter is in line with MD simulations on the PC/PS bilayer showing that the $\mathrm{C}$-terminal helical part of Lasio III is out of the membrane while a disordered N-terminal segment bearing the Trp anchors the peptide (Figure 6A). The latter is in close agreement with fluorescence and LD results suggesting a Trp side chain buried in the lipid bilayer (Figure 3A,D). The former also promotes that both the helical and the disordered regions can have a role in interacting with the membrane. In this case, the simultaneous presence of different secondary structures could open alternative ways compared to the fully helical structures, where further steps, such as oligomerization by interactions between, i.e., the disordered segments, followed by membrane insertions, could be easier foreseen. Note that longer sequences, such as the bee venom melittin $[79,100]$, or even LL-37 [31,37,61], will have some of their parts unfolded to some extent, and thus, belong more to mode II than I, depending on lipid composition and other environmental conditions. This may also provide more adaptability for longer sequences into various conditions, allowing potentially more widespread and diverse functionality.

\subsection{High Helicity, Non-Inserted, Perpendicular to Surface}

The third binding mode suggested here is for Tempo-La, which is significantly different from the first two. This ACP also adopts a helical conformation in the membrane-associated form according to CD and IR spectroscopy; however, as already discussed above, LD clearly demonstrates that the helix is perpendicular to the membrane surface (Figure 3B). Further, IR analysis of lipid perturbations (Figure 2), and MD simulations (Figure 6B,C), jointly suggest that this ACP is not inserted into the bilayer but is rather out of the membrane while attached to the lipids via its N-terminal part (Scheme 2). Based on simulations, in this binding mode, the helix has remarkable rotational flexibility, which allows the peptide to swing around in an antenna-like fashion. This distinct orientation can be best observed experimentally for PC/PS liposomes (Figure 3B), where the obtained LD signal is in line with the above binding mode, suggesting a preferentially perpendicular helix relative to the membrane surface. Based on MD, the ACP is attached to the surface by its LLR region, where the two N-terminal leucines are inserted more deeply into the headgroup region with connections to the hydrophobic chains, while the arginine side chain coordinates on the polar groups of the negatively charged lipids. Indeed, IR analysis revealed a slightly perturbed lipid phosphate region. Further on, intrinsic peptide fluorescence results (Figure 3E) indicate that Tempo-La is bound in a monomeric form to negatively charged membranes, as the quenching decreases in these cases with respect to the self-assembled non-bound peptide. This is further supported by measurements on REVs, as Tempo-La seems to be rather ineffective in removing the surface proteins compared to LL-37 and FK16, indicating that it most likely occupies much less surface space (Figure 7D). In summary, these results all suggest that Tempo-La is bound to the negatively charged bilayer surfaces in an uncommon way, in a monomeric, helical form, where the helix is in a flexible standing position that does not cover much space on the surface.

The observed categories clearly promote our understanding of different aspects of ACP membrane binding, which we hope provides further details on the structure-function relationships for ACPs. It should also be noted though, that these categories marked here can be clearly seen and identified for the shorter, $12-20$ residue sequences; nevertheless, for longer peptides, such as LL-37, it is likely that there is more than one sequential region where binding modes can alter within the same peptide. MD simulations, in fact, show that LL-37 has parts partially unfolded while membrane-bound, indicating that some regions, i.e., that of FK-16, adopt a highly helical binding mode, where other segments correspond more to the partially helical binding mode. Indeed, the solution NMR structure of LL-37 in a membrane-mimicking environment showed disordered segments at both termini and a kink at Lys12, preceding Gly14, separating a short and a long helix along the sequence [101]. In solid-state NMR experiments on lipid bilayers, including PG, high 
peptide helicity comprising residues 11-32 was supported, and a membrane disruption model that evolved from initial carpeting of the membrane surface was suggested [61].

Furthermore, our results on peptides with binding mode II are also in line with reported data using simple model systems mimicking a bacterial membrane composition. A membrane association mode resembling the one proposed here was suggested for Lasio III, including surface association and an anchoring N-terminal part using PC and PC/PG model vesicle systems [102], and helix formation only for the C-terminal part and inserted Trp of the N-terminal segment in micellar membrane-mimicking environment [1]. In an NMR study [21], the peptide was shown to adopt a curved helical conformation in a helix-promoting aqueous solution, attributed to the flexible part around the central Gly residue, which was suggested to play roles in its selectivity. Likewise, a partially helical state with a C-terminal ordered segment was indicated to some extent for Macro1 bound to SDS micelles [26]. For Tempo-La, while the current binding mode was identified on model vesicles, it is a likely scenario that such a stage will be an intermediate state that would progress in the presence of biological membranes, such as those of cancer cells, into a final membrane inserted and/or oligomeric phase, which is directly responsible for the anticancer activity. This is supported by the fact that pore formation was observed for Tempo-La on bacteria [28], which mechanism might be facilitated via a parallel positioning of the peptides relative to the lipids as revealed here for this peptide with negatively charged liposomes. Alternatively, this binding mode resembles the snorkelling or shifted helix model described for membrane-spanning proteins where the cationic but also highly hydrophobic Arg/Lys side chains contribute to positioning a partially inserted helix near the membrane surface [103-106]. Note, however, that for the latter examples, the effect of other sequential regions is unknown; thus, this comparison remains speculative at this point. Related, the experimental data may allow the co-existence of two peptide populations with parallel and perpendicular orientation with respect to the bilayer, respectively. However, this scenario is less likely based on computational results. Nevertheless, this interesting phenomenon for Tempo-La is worth investigating in detail, but at this point is beyond our current focus.

In this study, we focus on model vesicles composed of a few phospholipids to characterize ACP-membrane interactions. Biomembranes contain a tremendous variety of lipids with very diverse physicochemical properties determining membrane properties, e.g., curvature, surface charge, and fluidity, hard to mimic by simplistic models. Nevertheless, the binding modes described here can readily explain ACP actions observed on REVs, a more complex model system representing physiological-like lipid composition, with extra protein content. It is expected that once EVs from various cancer cells can be produced in quantities suitable for the above structural studies, we will be able to see further insight into mechanistic details of membrane-active compounds and, in particular, identify which types of cell membranes have the highest affinity to bind certain ACPs, aiding the identification of their optimal application areas. Finally, not only the membrane model but also the assay conditions should be considered in studies on peptide-membrane interaction, as highlighted recently [20,107-110]. In summary, with a critical view, the results presented here may provide a good assumption towards the in vivo action of the ACPs studied.

\section{Materials and Methods}

\subsection{Peptide Solutions}

Lasioglossin LL-III (MW = 1765.6), Macropin 1 (MW = 1416.8), Temporin-La (MW = 1622.6), FK-16 (MW = 2044.5), and LL-37 (MW = 4492.8) were synthesized by NovoPro Bioscience Inc. (Shanghai, China). Peptide purity corresponded to $\geq 95 \%$. For biophysical measurements, the lyophilized powder was dissolved in high purity water at $1 \mathrm{mM}$, aliquoted and stored frozen at $-18^{\circ} \mathrm{C}$. 


\subsection{Lipid Solutions}

High purity synthetic 1,2-dioleoyl-sn-glycero-3-phosphocholine (DOPC) and 1,2-dioleoyl-sn-glycero-3-[phospho-rac-(1-glycerol)], sodium salt (DOPG) was purchased from NOF (Tokyo, Japan) and 1,2-dioleoyl-sn-glycero-3-phospho-L-serine, sodium salt (DOPS) was purchased from Avanti Polar Lipids Inc (Sigma-Aldrich, Budapest, Hungary). Liposomes were prepared by using the lipid thin film hydration technique. Lipids were dissolved in chloroform (LabScan, Budapest, Hungary) containing 50\% vol methanol (Reanal, Budapest, Hungary), which was then evaporated using a rotary evaporator. The resulting lipid film was kept in a vacuum for at least $8 \mathrm{~h}$ to remove residual traces of solvent. The dried lipid film was hydrated with the assay buffer. After repeated heating $\left(37^{\circ} \mathrm{C}\right)$ and cooling $\left(-196^{\circ} \mathrm{C}\right)$ steps (at least 10 times), the solutions were extruded through polycarbonate filters with $100 \mathrm{~nm}$ pore size (at least 11 times) using a LIPEX extruder (Northern Lipids Inc., Burnaby, BC, Canada). Final lipid concentration was $13 \mathrm{mM}$. For mimicking mammalian, bacterial, and cancer cell membranes, pure DOPC, DOPC/DOPG $(80 / 20 \mathrm{n} / \mathrm{n} \%)$, and DOPC/DOPS $(80 / 20 \mathrm{n} / \mathrm{n} \%)$ referred to as PC, PC/PG, and PC/PS, respectively, were used thoroughly in the study.

\subsection{Assay Conditions}

The assay buffer used thoroughly in the study to mimic physiological conditions was isotonic phosphate-buffered saline (PBS, $10 \mathrm{mM}$ phosphate, $137 \mathrm{mM} \mathrm{NaCl}, 3 \mathrm{mM} \mathrm{KCl}$, $\mathrm{pH}$ 7.4), purchased from Sigma-Aldrich (Budapest, Hungary). For measuring CD spectra, a buffer avoiding chloride ions (10 $\mathrm{mM}$ Na-phosphate, $100 \mathrm{mM} \mathrm{Na}_{2} \mathrm{SO}_{4}, \mathrm{pH} 7.0, \mathrm{CD}$ buffer) was used frequently, which allowed spectra collection down to $190 \mathrm{~nm}$. In the case of LL-37, $\mathrm{CD}$ spectra were recorded in Tris- $\mathrm{HCl}$ buffer $(10 \mathrm{mM}, \mathrm{pH}$ 7.4). Furthermore, for collecting LD spectra, PBS containing 50\% wt sucrose was employed as sucrose has the advantage of reducing light scattering of liposomes by matching their refractive index [77].

\subsection{Red Blood-Cell Derived Extracellular Vesicles (REVs) Isolation}

Blood was collected from healthy adult volunteers $(\sim 15 \mathrm{~mL})$ in $\mathrm{K}_{3}$ EDTA containing tubes (Greiner Bio-One, Kremsmünster, Austria). The use of human blood samples was approved by the Scientific and Research Ethics Committee of the Hungarian Medical Research Council (ETT TUKEB 6449-2/2015), and during all procedures, we followed the guidelines and regulations of the declaration of Helsinki. Red blood cells (RBCs) were pelleted by centrifugation at $2500 \times \mathrm{g}$ for $10 \mathrm{~min}$ at $4{ }^{\circ} \mathrm{C}$ and washed three times with a physiological salt solution to achieve complete removal of buffy coats. RBCs were diluted with an equal volume of PBS and kept for 7 days at $4{ }^{\circ} \mathrm{C}$, allowing REVs production. After this period, RBCs and cellular debris were removed in two subsequent centrifugation steps, first at $2500 \times g$ for $15 \mathrm{~min}$ followed by $3000 \times g$ for $30 \mathrm{~min}$ at room temperature. The supernatant of the second centrifugation step containing REVs was further centrifuged at $16,000 \times g$ for $30 \mathrm{~min}$ at $4{ }^{\circ} \mathrm{C}$. The final pellet was resuspended in $100 \mu \mathrm{L}$ PBS and purified with size-exclusion chromatography (SEC) using a $3.5 \mathrm{~mL}$ gravity column filled with Sepharose CL-2B gel (GE Healthcare, Danderyd, Sweden). The REV sample was pipetted onto the column, followed by the addition of $900 \mu \mathrm{L}$ PBS while the flow-through was discarded. The purified REVs were eluted with PBS and collected in $1 \mathrm{~mL}$. The samples were stored at $4{ }^{\circ} \mathrm{C}$ and used within $72 \mathrm{~h}$ after isolation. We performed standardized biophysical characterizations for each REV preparation using the spectroscopic protein-tolipid ratio determination based on IR bands of the lipid $\mathrm{CH}$ and protein amide bands [68], which shows that this ratio is highly reproducible between preparations.

\subsection{Circular Dichroism (CD) Spectroscopy}

CD spectra were collected using a JASCO J-1500 spectropolarimeter at room temperature. CD spectra for peptide-liposome samples were collected in a $0.1 \mathrm{~cm}$ path-length cylindrical quartz cuvette (Hellma, Plainview, NY, USA) in continuous scanning mode between 190 and $260 \mathrm{~nm}$ at a rate of $50 \mathrm{~nm} / \mathrm{min}$, with a data pitch of $0.5 \mathrm{~nm}$, response time 
of $4 \mathrm{~s}, 1 \mathrm{~nm}$ bandwidth, and 3 times accumulation. CD spectra for the peptide-REVs samples were recorded on a Jasco J-715 spectropolarimeter in a $0.1 \mathrm{~cm}$ path-length rectangular quartz cuvette (Hellma, Plainview, NY, USA), using a continuous scanning mode between 197 and $270 \mathrm{~nm}$ at a rate of $100 \mathrm{~nm} / \mathrm{min}$ with a data pitch of $1 \mathrm{~nm}$, response time of $2 \mathrm{~s}$, $2 \mathrm{~nm}$ bandwidth, and 2 times accumulation. All spectra were corrected by subtracting a matching blank. To estimate the secondary structure of the peptides, the software BeStSel (http:/ / bestsel.elte.hu) [67] was used.

\subsection{Linear Dichroism (LD) Spectroscopy}

LD is defined as the differential absorption, $A$, between orthogonal forms of planepolarized light, where the polarization vector of the incident light beam is oriented parallel $\left(A_{\|}\right)$and perpendicular $\left(A_{\perp}\right)$ to the orientation axis of the sample:

$$
L D=A_{\|}-A_{\perp}
$$

$L D$ is used with systems that are either intrinsically oriented or are oriented during the experiment $[66,83]$. The sign and amplitude of the $L D$ signal at a particular transition depend on the direction along which the light passes through the oriented sample. In a macroscopically aligned system, chromophores will exhibit $L D$ if their transition moments have a preferential orientation relative to the orientation axis of the system. The alignment of liposomes can be achieved by shear flow in a rotation Couette cell device, resulting in ellipsoidal vesicles which align in the flow. Peptides that bind to the lipid surface in a nonrandom way will hence also be aligned, and their transition moments will exhibit $L D$ in the 190-300 nm spectral region [78,111,112]. Linear dichroism measurements were performed on a JASCO J-1500 spectropolarimeter equipped with a Couette flow cell system (CFC-573 Couette cell holder) with a total path length of $0.5 \mathrm{~mm}$. Spectra for the peptide-liposome samples were recorded between 195 and $400 \mathrm{~nm}$ at a rate of $100 \mathrm{~nm} / \mathrm{min}$ with a data pitch of $0.5 \mathrm{~nm}$, response time of $1 \mathrm{~s}$ and $1 \mathrm{~nm}$ bandwidth. The $L D$ spectra for the peptide-REVs samples were collected between 195 and $600 \mathrm{~nm}$ at a rate of $100 \mathrm{~nm} / \mathrm{min}$ with a data pitch of $0.5 \mathrm{~nm}$, response time of $1 \mathrm{~s}$, and $1 \mathrm{~nm}$ bandwidth. The peptide-liposome and peptide-REV samples were oriented under a shear gradient of $2270 \mathrm{~s}^{-1}$. Baselines at zero shear gradient were measured and subtracted from all spectra.

\subsection{Dynamic Light Scattering (DLS)}

Samples were measured at $20^{\circ} \mathrm{C}$ using a W130i dynamic light scattering device (DLS, Avid Nano Ltd., High Wycombe, UK) with a diode laser $(660 \mathrm{~nm})$ and a photodiode detector. Eppendorf disposable cuvettes (50-2000 $\mu \mathrm{L}$, UVette routine pack, Vienna, Austria, $\mathrm{GmbH}$ ) with $1 \mathrm{~cm}$ path-length were used. Samples containing 20 or $40 \mu \mathrm{M}$ peptide and 320 or $635 \mu \mathrm{M}$ lipid were measured in a final volume of $80 \mu \mathrm{L}$ in CD buffer, except for LL-37, for which Tris buffer was used. The time-dependent autocorrelation function was measured for $10 \mathrm{~s}$, repeated 10 times, and the average distributions were reported. Data analysis yielding the mean hydrodynamic diameter $(\mathrm{Dh})$ and polydispersity were performed with the iSize 3.0 software supplied with the device.

\subsection{Attenuated Total Reflection-Fourier Transform Infrared (ATR-FTIR) Spectroscopy}

FTIR spectroscopic measurements were conducted using a Varian 2000 FTIR Scimitar spectrometer (Varian Inc., Palo Alto, CA, USA) fitted with a liquid nitrogen-cooled mercurycadmium-telluride (MCT) detector and with a 'Golden Gate' single reflection diamond ATR accessory (Specac Ltd., Orpington, UK). Onto the diamond ATR surface, $5 \mu \mathrm{L}$ of the sample was mounted, and the spectrum was collected $\left(2 \mathrm{~cm}^{-1}\right.$ resolution and $\left.64 \mathrm{scans}\right)$ for a dry film after slow evaporation of the buffered solvent under ambient conditions. Each data acquisition was followed by ATR correction, and buffer subtraction and baseline corrections were performed. For peak identification, spectra were normalized by the area, and the second derivative was calculated. Spectra analysis was performed using the Origin software package (OriginLab, Northampton, MA, USA). 


\subsection{Transmission Electron Microscopy Combined with Freeze Fracture (FF-TEM)}

For direct visualization of the structure and morphology of the sample, FF-TEM images were obtained with a JEOL JEM-1400 transmission electron microscope (JEOL Ltd., Tokyo, Japan) operating at $120 \mathrm{kV}$. Images were captured routinely at magnifications of $\times 15,000,30,000$, and 60,000 and analyzed with SightX Viewer Software (EM-15300SXV Image Edit Software, JEOL Ltd., Tokyo, Japan). In detail, a droplet (approximately $2 \mu \mathrm{L}$ ) of the samples prepared in PBS (peptide and lipid concentrations were 80 and $2540 \mu \mathrm{M}$, respectively) were pipetted onto a golden sample holder and rapidly frozen in liquid freon $-194{ }^{\circ} \mathrm{C}$, then put into liquid nitrogen. The fracturing was performed in a Balzers freeze-fracture device at $-100{ }^{\circ} \mathrm{C}$ (Balzers BAF 400D, Balzers AG, Liechtenstein). A replica was made from the fractured surface with vaporized carbon-platinum. The replica was washed with surfactant solution and distilled water, and it was transferred to a 200 mesh copper grid with a support film made of formvar for measuring with the TEM equipment.

\subsection{Fluorescence Spectroscopy}

Fluorescence spectra for Lasio III and Tempo-La were recorded with a Jasco FP8500 spectrofluorometer at $25^{\circ} \mathrm{C}$ in PBS using 5 and $5 \mathrm{~nm}$ excitation and emission slits, respectively. The tryptophan fluorophore of Lasio III was excited at $295 \mathrm{~nm}$, and the emission was monitored from 305 to $400 \mathrm{~nm}$, while the tyrosine fluorophore in Tempo-La was excited at $275 \mathrm{~nm}$, and emission was monitored from 290 to $400 \mathrm{~nm}$. Binding assays were carried out at $2 \mu \mathrm{M}$ peptide and $100 \mathrm{uM}$ lipid. Blank spectra recorded for liposome solutions in the absence of peptides were subtracted.

\subsection{Molecular Dynamics Simulations}

All simulations were carried out by the GROMACS2018.3 [113,114] software, applying the CHARMM36m [115] force field. The initial, fully $\alpha$-helical structures of Lasio III, Macro1, Tempo-La, FK-16, and LL-37 were created by Avogadro 1.1.1 software [116]. Similarly to the liposome models used in the experimental measurements, $100 \mathrm{n} / \mathrm{n} \% \mathrm{PC}$, $80 / 20 \mathrm{n} / \mathrm{n} \%$ PC/PG and 80/20 n/n\% PC/PS bilayers were generated using the CHARMMGUI website [117,118], and the bilayers consisted of $128 \times 128$ lipids and $2 \mathrm{~nm}$ water layer on each side, respectively. The peptides were simulated with all the bilayers; hence, a sum of 15 simulations were performed. The following simulation protocol was applied in each case. First, each peptide was inserted into a simulation box with the exact same a, b unit cell vectors as the box of the applied bilayer, while the $c$ unit cell vector was chosen to be $5 \mathrm{~nm}$. The simulation box was then solvated by TIP3P water molecules, and the coordinates of the atoms in the box were translated to be on the top of the bilayer box. The third box with water molecules was also created to extend the water layer by $4 \mathrm{~nm}$ at the bottom layer. The three boxes were then merged, neutralized by $\mathrm{Na}^{+}$ions, and an excess of $150 \mathrm{mM} \mathrm{Na}^{+}$ and $\mathrm{Cl}^{-}$ions were added to mimic better physiological conditions.

Next, the systems were minimized and equilibrated in six steps. First, the systems were minimized for 5000 steps using the steepest descent algorithm. In the following two steps, the systems were heated up to $300 \mathrm{~K}$ temperature and simulated for 75 picoseconds using berendsen and then V-rescale thermostats $[119,120](\tau t=1.0 \mathrm{ps})$. In the last four steps, the systems were also coupled to a semiisotropic berendsen barostat [119] with 1 bar pressure $\left(\tau \mathrm{p}=5.0 \mathrm{ps}, \mathrm{kp}=4.5 \times 10^{-5} \mathrm{bar}^{-1}\right)$ and simulated for 650 picoseconds altogether. The applied position restraints on the peptide-heavy atoms and lipid phosphorous atoms were gradually switched off during the six steps of the minimization/equilibration process.

To ensure that the correct statistical NPT ensemble is sampled, the systems were coupled to a Nosé-Hoover thermostat [121] with $300 \mathrm{~K}$ temperature $(\tau t=1.0 \mathrm{ps})$ and a semiisotropic Parrinello-Rahman barostat [122] $\left(\tau \mathrm{p}=5.0 \mathrm{ps}, \mathrm{kp}=4.5 \times 10^{-5} \mathrm{bar}^{-1}\right)$ with 1 bar pressure during the production runs. Each system was simulated for 500 nanoseconds applying a 2 femtosecond time step. The electrostatics were treated by the Particle mesh Ewald (PME) method [123], and the cutoff was chosen to be $1.2 \mathrm{~nm}$ for the short-range 
electrostatic and van der Waals interactions. The LINCS algorithm [124] was used to constrain the hydrogen bonds. Periodic boundary conditions were applied in all directions.

The helicity of the peptides was calculated by the dssp method and defined as the number of the residues with $\alpha$-helical structure divided by the total number of the residues minus the two terminal residues, which is inherently considered to be a coil, due to the applied algorithm. The distance between the peptide and the surface of the bilayer was defined as the absolute value of the distance between the $\mathrm{z}$ coordinate of the centre of mass (COM) of the peptide atoms and the $\mathrm{z}$ coordinate of the COM of the phosphorous atoms of that particular leaflet which is closer to the peptide. The analyses were performed using GROMACS internal packages (do_dssp, distance), bash and python scripts, and the MDAnalysis [125] python package. The snapshots were created by the VMD 1.8.2 software [126]. Exponential averaging was used to smooth the curves.

\section{Conclusions}

In this study, we have investigated the membrane association mechanisms of five natural helical peptides with known anticancer activity. ACPs represent a promising alternative to conventional chemotherapy. Nevertheless, a better understanding of their mechanism of action on target cancer cell membranes is needed to enable improved design strategies on their selectivity, to realize their therapeutic potential. In this work, we show clear differences in their helicity and related selectivity towards model vesicles mimicking healthy and cancer cell membranes. Further on, we propose three different membraneassociation mechanisms for them, differing in the helix content of the peptides and the orientation of the helices relative to the membrane surface. LL-37 and its potent anticancer fragment FK-16 shared a common binding mode resembling the carpet model of classical antimicrobial peptides. Interestingly, peptide components of hymenopteran venom, Lasio III and Macro1, were classified to the same category, i.e., to a partially disordered binding mode on the surface, which suggests that these two peptides from similar sources dedicated to the same function share features in their action. Further, a unique mechanism and an "antenna-like" membrane association were revealed for Tempo-La, not yet described for membrane-active peptides. These findings provide further details into binding modes of the selected helical ACPs; however, it is expected that the identified categories can be applied to many other ACPs and, in general, also to antimicrobial peptides. Finally, it should be noted that, in line with recent results, the use of EVs as a more complex membrane system, incorporating host cell lipid and protein compositions, seem beneficial in gaining additional biophysical information on these systems, which cannot be obtained by simplified liposomal models.

Supplementary Materials: The following are available online at https:/ / www.mdpi.com/article/10 $.3390 /$ ijms22168613/s1.

Author Contributions: Conceptualization, M.Q.-P., T.J. and T.B.-S.; formal analysis, M.Q.-P., T.J., G.K., M.R. and T.B.-S.; funding acquisition, T.B.-S.; investigation, M.Q.-P., T.J., G.K., P.S., I.C.S., Z.I.P. and L.F.; methodology, M.Q.-P., T.J., G.K., P.S., I.C.S. and T.B.-S.; software, G.K.; supervision, T.J. and T.B.-S.; visualization, M.Q.-P., G.K. and M.R.; writing-original draft, M.Q.-P., T.J. and T.B.-S.; writing-review \& editing, M.Q.-P., T.J. and T.B.-S. All authors have read and agreed to the published version of the manuscript.

Funding: This study has been financially supported by the Hungarian Momentum Program (LP2016-2), the National Competitiveness and Excellence Program (NVKP_16-1-2016-0007), and the BIONANO_ GINOP-2.3.2-15-2016-00017 project.

Institutional Review Board Statement: The use of human blood samples in this study was conducted according to the guidelines and regulations of the Declaration of Helsinki and approved by the Scientific and Research Ethics Committee of the Hungarian Medical Research Council (ETT TUKEB 6449-2/2015).

Informed Consent Statement: Informed consent was obtained from all subjects involved in the study. 


\section{Data Availability Statement: Not applicable.}

Acknowledgments: The authors gratefully acknowledge Teréz Kiss (RCNS, Budapest, Hungary) for assisting with the preparation of FF-TEM samples.

Conflicts of Interest: The authors declare that they have no conflict of interest. The authors also declare they have no financial or non-financial interests in any material discussed in this manuscript.

\section{References}

1. Bandyopadhyay, S.; Lee, M.; Sivaraman, J.; Chatterjee, C. Model membrane interaction and DNA-binding of antimicrobial peptide Lasioglossin II derived from bee venom. Biochem. Biophys. Res. Commun. 2013, 430, 1-6. [CrossRef] [PubMed]

2. Gabernet, G.; Müller, A.T.; Hiss, J.A.; Schneider, G. Membranolytic anticancer peptides. MedChemComm 2016, 7, $2232-2245$. [CrossRef]

3. Gaspar, D.; Veiga, A.S.; Castanho, M.A. From antimicrobial to anticancer peptides. A review. Front. Microbiol. 2013, 4, 294. [CrossRef]

4. Bray, F.; Ferlay, J.; Soerjomataram, I.; Siegel, R.L.; Torre, L.A.; Jemal, A. Global cancer statistics 2018: GLOBOCAN estimates of incidence and mortality worldwide for 36 cancers in 185 countries. CA Cancer J. Clin. 2018, 68, 394-424. [CrossRef]

5. Riedl, S.; Zweytick, D.; Lohner, K. Membrane-active host defense peptides-challenges and perspectives for the development of novel anticancer drugs. Chem. Phys. Lipids 2011, 164, 766-781. [CrossRef]

6. Xie, M.; Liu, D.; Yang, Y. Anti-cancer peptides: Classification, mechanism of action, reconstruction and modification. Open Biol. 2020, 10, 200004. [CrossRef]

7. Lambert, A.W.; Pattabiraman, D.R.; Weinberg, R.A. Emerging biological principles of metastasis. Cell 2017, 168, 670-691. [CrossRef]

8. Hilchie, A.; Hoskin, D.; Coombs, M.P. Anticancer activities of natural and synthetic peptides. Antimicrob. Pept. 2019, 1117, 131-147.

9. Magana, M.; Pushpanathan, M.; Santos, A.L.; Leanse, L.; Fernandez, M.; Ioannidis, A.; Giulianotti, M.A.; Apidianakis, Y.; Bradfute, S.; Ferguson, A.L. The value of antimicrobial peptides in the age of resistance. Lancet Infect. Dis. 2020, 20, e216-e230. [CrossRef]

10. Pan, $\mathrm{X} . ; \mathrm{Xu}, \mathrm{J} . ; \mathrm{Jia}, \mathrm{X}$. Research progress evaluating the function and mechanism of anti-tumor peptides. Cancer Manag. Res. 2020, 12, 397. [CrossRef] [PubMed]

11. Pirtskhalava, M.; Amstrong, A.A.; Grigolava, M.; Chubinidze, M.; Alimbarashvili, E.; Vishnepolsky, B.; Gabrielian, A.; Rosenthal, A.; Hurt, D.E.; Tartakovsky, M. DBAASP v3: Database of antimicrobial/cytotoxic activity and structure of peptides as a resource for development of new therapeutics. Nucleic Acids Res. 2021, 49, D288-D297. [CrossRef] [PubMed]

12. Hancock, R.E.; Sahl, H.-G. Antimicrobial and host-defense peptides as new anti-infective therapeutic strategies. Nat. Biotechnol. 2006, 24, 1551-1557. [CrossRef] [PubMed]

13. Bechinger, B.; Lohner, K. Detergent-like actions of linear amphipathic cationic antimicrobial peptides. Biochim. Biophys. Acta Biomembr. 2006, 1758, 1529-1539. [CrossRef] [PubMed]

14. Schweizer, F. Cationic amphiphilic peptides with cancer-selective toxicity. Eur. J. Pharmacol. 2009, 625, 190-194. [CrossRef]

15. Matsuzaki, K. Membrane permeabilization mechanisms. Antimicrob. Pept. 2019, 1117, 9-16.

16. Epand, R.M.; Vogel, H.J. Diversity of antimicrobial peptides and their mechanisms of action. Biochim. Biophys. Acta Biomembr. 1999, 1462, 11-28. [CrossRef]

17. Hallock, K.J.; Lee, D.-K.; Omnaas, J.; Mosberg, H.I.; Ramamoorthy, A. Membrane composition determines pardaxin's mechanism of lipid bilayer disruption. Biophys. J. 2002, 83, 1004-1013. [CrossRef]

18. Zelezetsky, I.; Tossi, A. Alpha-helical antimicrobial peptides-Using a sequence template to guide structure-activity relationship studies. Biochim. Biophys. Acta Biomembr. 2006, 1758, 1436-1449. [CrossRef]

19. Almeida, P.F.; Pokorny, A. Mechanisms of antimicrobial, cytolytic, and cell-penetrating peptides: From kinetics to thermodynamics. Biochemistry 2009, 48, 8083-8093. [CrossRef] [PubMed]

20. Sevcsik, E.; Pabst, G.; Richter, W.; Danner, S.; Amenitsch, H.; Lohner, K. Interaction of LL-37 with model membrane systems of different complexity: Influence of the lipid matrix. Biophys. J. 2008, 94, 4688-4699. [CrossRef] [PubMed]

21. Čeřovský, V.; Buděšínský, M.; Hovorka, O.; Cvačka, J.; Voburka, Z.; Slaninová, J.; Borovičková, L.; Fučík, V.; Bednárová, L.; Votruba, I. Lasioglossins: Three novel antimicrobial peptides from the venom of the eusocial bee Lasioglossum laticeps (Hymenoptera: Halictidae). ChemBioChem 2009, 10, 2089-2099. [CrossRef]

22. Tonk, M.; Vilcinskas, A.; Rahnamaeian, M. Insect antimicrobial peptides: Potential tools for the prevention of skin cancer. Appl. Microbiol. Biotechnol. 2016, 100, 7397-7405. [CrossRef]

23. Mishra, B.; Basu, A.; Saravanan, R.; Xiang, L.; Yang, L.K.; Leong, S.S.J. Lasioglossin-III: Antimicrobial characterization and feasibility study for immobilization applications. RSC Adv. 2013, 3, 9534-9543. [CrossRef]

24. Slaninová, J.; Mlsová, V.; Kroupová, H.; Alán, L.; Tůmová, T.; Monincová, L.; Borovičková, L.; Fučík, V.; Čeřovský, V. Toxicity study of antimicrobial peptides from wild bee venom and their analogs toward mammalian normal and cancer cells. Peptides 2012, 33, 18-26. [CrossRef] [PubMed]

25. Ko, S.J.; Kim, M.K.; Bang, J.K.; Seo, C.H.; Luchian, T.; Park, Y. Macropis fulvipes venom component Macropin exerts its antibacterial and anti-biofilm properties by damaging the plasma membranes of drug resistant bacteria. Sci. Rep. 2017, 7, 1-14. [CrossRef] [PubMed] 
26. Monincová, L.; Veverka, V.; Slaninová, J.; Buděšínský, M.; Fučík, V.; Bednárová, L.; Straka, J.; Čeřovský, V. Structure-activity study of macropin, a novel antimicrobial peptide from the venom of solitary bee Macropis fulvipes (Hymenoptera: Melittidae). J. Pept. Sci. 2014, 20, 375-384. [CrossRef]

27. Zhao, R.-L.; Han, J.-Y.; Han, W.-Y.; He, H.-X.; Ma, J.-F. Effects of Two Novel Peptides from Skin of Lithobates catesbeianus on Tumor cell Morphology and Proliferation. In Molecular Cloning-Selected Applications in Medicine and Biology; IntechOpen: London, UK, 2011; p. 73. [CrossRef]

28. Zhao, R.-L.; Han, J.-Y.; Han, W.-Y.; Lei, L.-C.; Sun, C.-J.; Feng, X.; Jiang, L.-N.; Qiao, H.-W.; Cai, L.-J. Molecular cloning of two novel temporins from Lithobates catesbeianus and studying of their antimicrobial mechanisms. Prog. Biochem. Biophys. 2009, 36, 1064-1070. [CrossRef]

29. Diao, Y.; Han, W.; Zhao, H.; Zhu, S.; Liu, X.; Feng, X.; Gu, J.; Yao, C.; Liu, S.; Sun, C.; et al. Designed synthetic analogs of the $\alpha$-helical peptide temporin-La with improved antitumor efficacies via charge modification and incorporation of the integrin $\alpha \mathrm{v} \beta 3$ homing domain. J. Pept. Sci. 2012, 18, 476-486. [CrossRef]

30. Zsila, F.; Kohut, G.; Beke-Somfai, T. Disorder-to-helix conformational conversion of the human immunomodulatory peptide LL-37 induced by antiinflammatory drugs, food dyes and some metabolites. Int. J. Biol. Macromol. 2019, 129, 50-60. [CrossRef]

31. Burton, M.F.; Steel, P.G. The chemistry and biology of LL-37. Nat. Prod. Rep. 2009, 26, 1572-1584. [CrossRef]

32. Kuroda, K.; Okumura, K.; Isogai, H.; Isogai, E. The human cathelicidin antimicrobial peptide LL-37 and mimics are potential anticancer drugs. Front. Oncol. 2015, 5, 144. [CrossRef] [PubMed]

33. Verjans, E.-T.; Zels, S.; Luyten, W.; Landuyt, B.; Schoofs, L. Molecular mechanisms of LL-37-induced receptor activation: An. overview. Peptides 2016, 85, 16-26. [CrossRef]

34. Sørensen, O.E.; Follin, P.; Johnsen, A.H.; Calafat, J.; Tjabringa, G.S.; Hiemstra, P.S.; Borregaard, N. Human cathelicidin, hCAP-18, is processed to the antimicrobial peptide LL-37 by extracellular cleavage with proteinase 3. Blood 2001, 97, 3951-3959. [CrossRef]

35. Ren, S.X.; Shen, J.; Cheng, A.S.; Lu, L.; Chan, R.L.; Li, Z.J.; Wang, X.J.; Wong, C.C.; Zhang, L.; Ng, S.S. FK-16 derived from the anticancer peptide LL-37 induces caspase-independent apoptosis and autophagic cell death in colon cancer cells. PLoS ONE 2013, 8, e63641. [CrossRef]

36. Mishra, B.; Wang, G. Titanium surfaces immobilized with the major antimicrobial fragment FK-16 of human cathelicidin LL-37 are potent against multiple antibiotic-resistant bacteria. Biofouling 2017, 33, 544-555. [CrossRef] [PubMed]

37. Li, X.; Li, Y.; Han, H.; Miller, D.W.; Wang, G. Solution structures of human LL-37 fragments and NMR-based identification of a minimal membrane-targeting antimicrobial and anticancer region. J. Am. Chem. Soc. 2006, 128, 5776-5785. [CrossRef]

38. Wang, G. Structures of human host defense cathelicidin LL-37 and its smallest antimicrobial peptide KR-12 in lipid micelles. J. Biol. Chem. 2008, 283, 32637-32643. [CrossRef]

39. Sok, M.; Šentjurc, M.; Schara, M. Membrane fluidity characteristics of human lung cancer. Cancer Lett. 1999, 139, 215-220. [CrossRef]

40. Hoskin, D.W.; Ramamoorthy, A. Studies on anticancer activities of antimicrobial peptides. Biochim. Biophys. Acta Biomembr. 2008, 1778, 357-375. [CrossRef]

41. Riedl, S.; Rinner, B.; Asslaber, M.; Schaider, H.; Walzer, S.; Novak, A.; Lohner, K.; Zweytick, D. In search of a novel targetphosphatidylserine exposed by non-apoptotic tumor cells and metastases of malignancies with poor treatment efficacy. Biochim. Biophys. Acta Biomembr. 2011, 1808, 2638-2645. [CrossRef]

42. Papo, N.; Shai, Y. Host defense peptides as new weapons in cancer treatment. Cell. Mol. Life Sci. 2005, 62, 784-790. [CrossRef]

43. Tripisciano, C.; Weiss, R.; Karuthedom George, S.; Fischer, M.B.; Weber, V. Extracellular Vesicles Derived From Platelets, Red Blood Cells, and Monocyte-Like Cells Differ. Regarding Their Ability to Induce Factor XII-Dependent Thrombin Generation. Front. Cell Dev. Biol. 2020, 8, 298. [CrossRef]

44. Jørgensen, M.M.; Bæk, R.; Varming, K. Potentials and capabilities of the Extracellular Vesicle (EV) Array. J. Extracell. Vesicles 2015, 4, 26048. [CrossRef]

45. Thangaraju, K.; Neerukonda, S.N.; Katneni, U.; Buehler, P.W. Extracellular Vesicles from Red Blood Cells and Their Evolving Roles in Health, Coagulopathy and Therapy. Int. J. Mol. Sci. 2021, 22, 153. [CrossRef]

46. Usman, W.M.; Pham, T.C.; Kwok, Y.Y.; Vu, L.T.; Ma, V.; Peng, B.; San Chan, Y.; Wei, L.; Chin, S.M.; Azad, A. Efficient RNA drug delivery using red blood cell extracellular vesicles. Nat. Commun. 2018, 9, 1-15. [CrossRef] [PubMed]

47. Fauchere, J. Hydrophobic Parameters Pi of Amino-Acid Side Chains from The Partitioning Of N-Acetyl-Amino Amides. Eur. J. Med. Chem. 1983, 18, 369-375.

48. Gautier, R.; Douguet, D.; Antonny, B.; Drin, G. Heliquest: A web server to screen sequences with specific $\alpha$-helical properties. Bioinformatics 2008, 24, 2101-2102. [CrossRef]

49. Eisenberg, D.; Schwarz, E.; Komaromy, M.; Wall, R. Analysis of membrane and surface protein sequences with the hydrophobic moment plot. J. Mol. Biol. 1984, 179, 125-142. [CrossRef]

50. Eisenberg, D.; Weiss, R.M.; Terwilliger, T.C. The helical hydrophobic moment: A measure of the amphiphilicity of a helix. Nature 1982, 299, 371-374. [CrossRef]

51. Piktel, E.; Niemirowicz, K.; Wnorowska, U.; Wątek, M.; Wollny, T.; Głuszek, K.; Góźdź, S.; Levental, I.; Bucki, R. The role of cathelicidin LL-37 in cancer development. Arch. Immunol. Ther. Exp. 2016, 64, 33-46. [CrossRef] [PubMed]

52. Mohammed, I.; Said, D.G.; Nubile, M.; Mastropasqua, L.; Dua, H.S. Cathelicidin-derived synthetic peptide improves therapeutic potential of vancomycin against Pseudomonas aeruginosa. Front. Microbiol. 2019, 10, 2190. [CrossRef] 
53. Quemé-Peña, M.; Ricci, M.; Juhász, T.; Horváti, K.; Bősze, S.; Biri-Kovács, B.; Szeder, B.; Zsila, F.; Beke-Somfai, T. Old Polyanionic Drug Suramin Suppresses Detrimental Cytotoxicity of the Host Defense Peptide LL-37. ACS Pharmacol. Transl. Sci. 2020, 4, 155-167. [CrossRef]

54. Nan, Y.H.; Bang, J.-K.; Jacob, B.; Park, I.-S.; Shin, S.Y. Prokaryotic selectivity and LPS-neutralizing activity of short antimicrobial peptides designed from the human antimicrobial peptide LL-37. Peptides 2012, 35, 239-247. [CrossRef] [PubMed]

55. Oren, Z.; Lerman, J.C.; Gudmundsson, G.H.; Agerberth, B.; Shai, Y. Structure and organization of the human antimicrobial peptide LL-37 in phospholipid membranes: Relevance to the molecular basis for its non-cell-selective activity. Biochem. J. 1999, 341, 501-513. [CrossRef]

56. Ciornei, C.D.; Sigurdardóttir, T.; Schmidtchen, A.; Bodelsson, M. Antimicrobial and chemoattractant activity, lipopolysaccharide neutralization, cytotoxicity, and inhibition by serum of analogs of human cathelicidin LL-37. Antimicrob. Agents Chemother. 2005, 49, 2845-2850. [CrossRef]

57. Ren, S.X.; Cheng, A.S.; To, K.F.; Tong, J.H.; Li, M.S.; Shen, J.; Wong, C.C.; Zhang, L.; Chan, R.L.; Wang, X.J. Host immune defense peptide LL-37 activates caspase-independent apoptosis and suppresses colon cancer. Cancer Res. 2012, 72, 6512-6523. [CrossRef] [PubMed]

58. Wu, W.K.K.; Sung, J.J.Y.; To, K.F.; Yu, L.; Li, H.T.; Li, Z.J.; Chu, K.M.; Yu, J.; Cho, C.H. The host defense peptide LL-37 activates the tumor-suppressing bone morphogenetic protein signaling via inhibition of proteasome in gastric cancer cells. J. Cell. Physiol. 2010, 223, 178-186. [CrossRef]

59. Mader, J.S.; Mookherjee, N.; Hancock, R.E.; Bleackley, R.C. The Human Host Defense Peptide LL-37 Induces Apoptosis in a Calpain-and Apoptosis-Inducing Factor-Dependent Manner Involving Bax Activity. Mol. Cancer Res. 2009, 7, 689-702. [CrossRef] [PubMed]

60. Wang, G.; Narayana, J.L.; Mishra, B.; Zhang, Y.; Wang, F.; Wang, C.; Zarena, D.; Lushnikova, T.; Wang, X. Design of antimicrobial peptides: Progress made with human cathelicidin LL-37. Antimicrob. Pept. 2019, 1117, 215-240. [CrossRef]

61. Henzler Wildman, K.A.; Lee, D.-K.; Ramamoorthy, A. Mechanism of lipid bilayer disruption by the human antimicrobial peptide, LL-37. Biochemistry 2003, 42, 6545-6558. [CrossRef]

62. Reißer, S.; Prock, S.; Heinzmann, H.; Ulrich, A.S. Protein ORIGAMI: A program for the creation of 3D paper models of folded peptides. Biochem. Mol. Biol. Educ. 2018, 46, 403-409. [CrossRef]

63. Xhindoli, D.; Pacor, S.; Benincasa, M.; Scocchi, M.; Gennaro, R.; Tossi, A. The human cathelicidin LL-37-A pore-forming antibacterial peptide and host-cell modulator. Biochim. Biophys. Acta Biomembr. 2016, 1858, 546-566. [CrossRef]

64. Johansson, J.; Gudmundsson, G.H.; Rottenberg, M.n.E.; Berndt, K.D.; Agerberth, B. Conformation-dependent antibacterial activity of the naturally occurring human peptide LL-37. J. Biol. Chem. 1998, 273, 3718-3724. [CrossRef]

65. Woody, R.W. Circular dichroism of intrinsically disordered proteins. In Instrumental Analysis of Intrinsically Disordered Proteins: Assessing Structure and Conformation; John Wiley \& Sons: Hoboken, NJ, USA, 2010; pp. 303-321.

66. Nordén, B.; Rodger, A.; Dafforn, T. Linear Dichroism and Circular Dichroism; The Royal Society of Chemistry: London, UK, 2010.

67. Micsonai, A.; Wien, F.; Kernya, L.; Lee, Y.-H.; Goto, Y.; Réfrégiers, M.; Kardos, J. Accurate secondary structure prediction and fold recognition for circular dichroism spectroscopy. Proc. Natl. Acad. Sci. USA 2015, 112, E3095-E3103. [CrossRef]

68. Mihály, J.; Deák, R.; Szigyártó, I.C.; Bóta, A.; Beke-Somfai, T.; Varga, Z. Characterization of extracellular vesicles by IR spectroscopy: Fast and simple classification based on amide and CH stretching vibrations. Biochim. Biophys. Acta Biomembr. 2017, 1859, 459-466. [CrossRef]

69. Deák, R.; Mihály, J.; Szigyártó, I.C.; Wacha, A.; Lelkes, G.; Bóta, A. Physicochemical characterization of artificial nanoerythrosomes derived from erythrocyte ghost membranes. Colloids Surf. B Biointerfaces 2015, 135, 225-234. [CrossRef] [PubMed]

70. Vigano, C.; Manciu, L.; Buyse, F.; Goormaghtigh, E.; Ruysschaert, J.M. Attenuated total reflection IR spectroscopy as a tool to investigate the structure, orientation and tertiary structure changes in peptides and membrane proteins. Pept. Sci. 2000, 55, 373-380. [CrossRef]

71. Dluhy, R.A.; Stephens, S.M.; Widayati, S.; Williams, A.D. Vibrational spectroscopy of biophysical monolayers. Applications of IR and Raman spectroscopy to biomembrane model systems at interfaces. Spectrochim. Acta Part A Mol. Biomol. Spectrosc. 1995, 51, 1413-1447. [CrossRef]

72. Schibli, D.J.; Epand, R.F.; Vogel, H.J.; Epand, R.M. Tryptophan-rich antimicrobial peptides: Comparative properties and membrane interactions. Biochem. Cell Biol. 2002, 80, 667-677. [CrossRef] [PubMed]

73. Bóta, A.; Wacha, A.; Varga, Z.; Csilla Szigyártó, I.; Kristyán, S.; Lőrincz, A.; Szabó, P.; Kálmán, M.; Naszályi-Nagy , L.; Mihály, J Role of oligo (malic acid) on the formation of unilamellar vesicles. J. Colloid Interface Sci. 2018, 532, 782-789. [CrossRef] [PubMed]

74. Lewis, R.N.; McElhaney, R.N. Membrane lipid phase transitions and phase organization studied by Fourier transform infrared spectroscopy. Biochim. Biophys. Acta Biomembr. 2013, 1828, 2347-2358. [CrossRef] [PubMed]

75. Nicolini, C.; Kraineva, J.; Khurana, M.; Periasamy, N.; Funari, S.S.; Winter, R. Temperature and pressure effects on structural and conformational properties of POPC/SM/cholesterol model raft mixtures-A FT-IR, SAXS, DSC, PPC and Laurdan fluorescence spectroscopy study. Biochim. Biophys. Acta Biomembr. 2006, 1758, 248-258. [CrossRef] [PubMed]

76. Moore, D.J.; Sills, R.H.; Patel, N.; Mendelsohn, R. Conformational order of phospholipids incorporated into human erythrocytes: An FTIR spectroscopy study. Biochemistry 1996, 35, 229-235. [CrossRef]

77. Rocha, S.; Kogan, M.; Beke-Somfai, T.; Nordén, B. Probing Microscopic Orientation in Membranes by Linear Dichroism. Langmuir 2016, 32, 2841-2846. [CrossRef] [PubMed] 
78. Esbjörner, E.K.; Oglecka, K.; Lincoln, P.; Gräslund, A.; Nordén, B. Membrane binding of pH-sensitive influenza fusion peptides. Positioning, configuration, and induced leakage in a lipid vesicle model. Biochemistry 2007, 46, 13490-13504. [CrossRef] [PubMed]

79. Svensson, F.R.; Lincoln, P.; Nordén, B.; Esbjörner, E.K. Tryptophan orientations in membrane-bound gramicidin and melittin-a comparative linear dichroism study on transmembrane and surface-bound peptides. Biochim. Biophys. Acta Biomembr. 2011, 1808, 219-228. [CrossRef]

80. Fornander, L.H.; Feng, B.; Beke-Somfai, T.S.; Nordén, B. UV transition moments of tyrosine. J. Phys. Chem. B 2014, 118, 9247-9257. [CrossRef]

81. Caesar, C.E.; Esbjörner, E.K.; Lincoln, P.; Nordén, B. Membrane interactions of cell-penetrating peptides probed by tryptophan fluorescence and dichroism techniques: Correlations of structure to cellular uptake. Biochemistry 2006, 45, 7682-7692. [CrossRef]

82. Rodger, A.; Dorrington, G.; Ang, D.L. Linear dichroism as a probe of molecular structure and interactions. Analyst 2016, 141, 6490-6498. [CrossRef]

83. Hicks, M.R.; Kowałski, J.; Rodger, A. LD spectroscopy of natural and synthetic biomaterials. Chem. Soc. Rev. 2010, 39, 3380-3393. [CrossRef]

84. Caesar, C.E.; Esbjörner, E.K.; Lincoln, P.; Nordén, B. Assigning membrane binding geometry of cytochrome C by polarized light spectroscopy. Biophys. J. 2009, 96, 3399-3411. [CrossRef]

85. Brattwall, C.E.; Lincoln, P.; Nordén, B. Orientation and conformation of cell-penetrating peptide penetratin in phospholipid vesicle membranes determined by polarized-light spectroscopy. J. Am. Chem. Soc. 2003, 125, 14214-14215. [CrossRef]

86. Arias, M.; Nguyen, L.T.; Kuczynski, A.M.; Lejon, T.; Vogel, H.J. Position-dependent influence of the three trp residues on the membrane activity of the antimicrobial peptide, tritrpticin. Antibiotics 2014, 3, 595-616. [CrossRef]

87. Kohn, E.M.; Shirley, D.J.; Arotsky, L.; Picciano, A.M.; Ridgway, Z.; Urban, M.W.; Carone, B.R.; Caputo, G.A. Role of cationic side chains in the antimicrobial activity of C18G. Molecules 2018, 23, 329. [CrossRef] [PubMed]

88. Chen, C.H.; Starr, C.G.; Guha, S.; Wimley, W.C.; Ulmschneider, M.B.; Ulmschneider, J.P. Tuning of a membrane-perforating antimicrobial peptide to selectively target membranes of different lipid composition. J. Membr. Biol. 2021, 254, 75-96. [CrossRef]

89. Ricci, M.; Horváti, K.; Juhász, T.; Szigyártó, I.; Török, G.; Sebák, F.; Bodor, A.; Homolya, L.; Henczkó, J.; Pályi, B.; et al. Anionic food color tartrazine enhances antibacterial efficacy of histatin-derived peptide DHVAR4 by fine-tuning its membrane activity. $Q$. Rev. Biophys. 2020, 53, E5. [CrossRef] [PubMed]

90. Zhang, D.X.; Kiomourtzis, T.; Lam, C.K.; Le, M.T. The biology and therapeutic applications of red blood cell extracellular vesicles. In Erythrocyte; IntechOpen: London, UK, 2019.

91. Deák, R.; Mihály, J.; Szigyártó, I.C.; Beke-Somfai, T.; Turiák, L.; Drahos, L.; Wacha, A.; Bóta, A.; Varga, Z. Nanoerythrosomes tailoring: Lipid induced protein scaffolding in ghost membrane derived vesicles. Mater. Sci. Eng. C 2020, 109, 110428. [CrossRef]

92. Singh, P.; Szigyártó, I.C.; Ricci, M.; Zsila, F.; Juhász, T.; Mihály, J.; Bősze, S.; Bulyáki, E.; Kardos, J.; Kitka, D.; et al. Membrane active peptides remove surface adsorbed protein corona from extracellular vesicles of red blood cells. Front. Chem. 2020, 8, 703. [CrossRef] [PubMed]

93. Szigyártó, I.C.; Deák, R.; Mihály, J.; Rocha, S.; Zsila, F.; Varga, Z.; Beke-Somfai, T. Flow Alignment of Extracellular Vesicles: Structure and Orientation of Membrane-Associated Bio-macromolecules Studied with Polarized Light. ChemBioChem 2018, 19, 545-551. [CrossRef] [PubMed]

94. Matsuzaki, K. Why and how are peptide-lipid interactions utilized for self-defense? Magainins and tachyplesins as archetypes. Biochim. Biophys. Acta Biomembr. 1999, 1462, 1-10. [CrossRef]

95. Quemé-Peña, M.; Juhász, T.; Mihály, J.; Szigyártó, I.C.; Horváti, K.; Bősze, S.; Henczkó, J.; Pályi, B.; Németh, C.; Varga, Z.; et al. Manipulating Active Structure and Function of Cationic Antimicrobial Peptide CM15 by the Polysulfonated Drug Suramin: A Step Closer to in vivo Complexity. ChemBioChem 2019, 20, 1578. [CrossRef]

96. Locock, K.E.S. Bioinspired Polymers: Antimicrobial Polymethacrylates. Aust. J. Chem. 2016, 69, 717-724. [CrossRef]

97. Van den Bergen, G.; Stroet, M.; Caron, B.; Poger, D.; Mark, A.E. Curved or linear? Predicting the 3-dimensional structure of $\alpha$-helical antimicrobial peptides in an amphipathic environment. FEBS Lett. 2020, 594, 1062-1080. [CrossRef] [PubMed]

98. Pathak, N.; Salas-Auvert, R.; Ruche, G.; Janna, M.h.; McCarthy, D.; Harrison, R.G. Comparison of the effects of hydrophobicity, amphiphilicity, and $\alpha$-helicity on the activities of antimicrobial peptides. Proteins Struct. Funct. Bioinform. 1995, 22, 182-186. [CrossRef] [PubMed]

99. Brogden, K.A. Antimicrobial peptides: Pore formers or metabolic inhibitors in bacteria? Nat. Rev. Microbiol. 2005, 3, 238. [CrossRef]

100. Sato, H.; Feix, J.B. Peptide-membrane interactions and mechanisms of membrane destruction by amphipathic $\alpha$-helical antimicrobial peptides. Biochim. Biophys. Acta Biomembr. 2006, 1758, 1245-1256. [CrossRef] [PubMed]

101. Porcelli, F.; Verardi, R.; Shi, L.; Henzler-Wildman, K.A.; Ramamoorthy, A.; Veglia, G. NMR structure of the cathelicidin-derived human antimicrobial peptide LL-37 in dodecylphosphocholine micelles. Biochemistry 2008, 47, 5565-5572. [CrossRef]

102. Battista, F.; Oliva, R.; Del Vecchio, P.; Winter, R.; Petraccone, L. Insights into the Action Mechanism of the Antimicrobial Peptide Lasioglossin III. Int. J. Mol. Sci. 2021, 22, 2857. [CrossRef]

103. Caputo, G.A.; London, E. Cumulative effects of amino acid substitutions and hydrophobic mismatch upon the transmembrane stability and conformation of hydrophobic $\alpha$-helices. Biochemistry 2003, 42, 3275-3285. [CrossRef]

104. Jafari, M.; Mehrnejad, F.; Doustdar, F. Insight into the interactions, residue snorkeling, and membrane disordering potency of a single antimicrobial peptide into different lipid bilayers. PLoS ONE 2017, 12, e0187216. [CrossRef] 
105. Li, H.; Yan, C.; Guo, J.; Xu, C. Ionic protein-lipid interactions at the plasma membrane regulate the structure and function of immunoreceptors. Adv. Immunol. 2019, 144, 65-85.

106. Mishra, V.; Palgunachari, M.; Segrest, J.; Anantharamaiah, G. Interactions of synthetic peptide analogs of the class A amphipathic helix with lipids. Evidence for the snorkel hypothesis. J. Biol. Chem. 1994, 269, 7185-7191. [CrossRef]

107. Hazam, P.K.; Akhil, R.; Jerath, G.; Saikia, J.; Ramakrishnan, V. Topological effects on the designability and bactericidal potency of antimicrobial peptides. Biophys. Chem. 2019, 248, 1-8. [CrossRef]

108. Pandidan, S.; Mechler, A. Membrane morphology effects in quartz crystal microbalance characterization of antimicrobial peptide activity. Biophys. Chem. 2020, 262, 106381. [CrossRef] [PubMed]

109. Travers, W.; Kelleher, F. Studies of the highly potent lantibiotic peptide nisin $\mathrm{Z}$ in aqueous solutions of salts and biological buffer components. Biophys. Chem. 2021, 274, 106603. [CrossRef]

110. Santana, H.J.A.; Caseli, L. A bactericide peptide changing the static and dilatational surface elasticity properties of zwitterionic lipids at the air-water interface: Relationship with the thermodynamic, structural and morphological properties. Biophys. Chem. 2021, 277, 106638. [CrossRef] [PubMed]

111. Svensson, F.R.; Lincoln, P.; Nordén, B.; Esbjörner, E.K. Retinoid chromophores as probes of membrane lipid order. J. Phys. Chem. B 2007, 111, 10839-10848. [CrossRef]

112. Ardhammar, M.; Mikati, N.; Nordén, B. Chromophore orientation in liposome membranes probed with flow dichroism. J. Am. Chem. Soc. 1998, 120, 9957-9958. [CrossRef]

113. Berendsen, H.J.; van der Spoel, D.; van Drunen, R. Gromacs: A message-passing parallel molecular dynamics implementation. Comput. Phys. Commun. 1995, 91, 43-56. [CrossRef]

114. Abraham, M.J.; Murtola, T.; Schulz, R.; Páll, S.; Smith, J.C.; Hess, B.; Lindahl, E. Gromacs: High. performance molecular simulations through multi-level parallelism from laptops to supercomputers. SoftwareX 2015, 1, 19-25. [CrossRef]

115. Huang, J.; Rauscher, S.; Nawrocki, G.; Ran, T.; Feig, M.; de Groot, B.L.; Grubmüller, H.; MacKerell, A.D. CHARMM36m: An improved force field for folded and intrinsically disordered proteins. Nat. Methods 2017, 14, 71-73. [CrossRef] [PubMed]

116. Hanwell, M.D.; Curtis, D.E.; Lonie, D.C.; Vandermeersch, T.; Zurek, E.; Hutchison, G.R. Avogadro: An advanced semantic chemical editor, visualization, and analysis platform. J. Cheminform. 2012, 4, 17. [CrossRef] [PubMed]

117. Jo, S.; Kim, T.; Iyer, V.G.; Im, W. CHARMM-GUI: A web-based graphical user interface for CHARMM. J. Comput. Chem. 2008, 29, 1859-1865. [CrossRef]

118. Jo, S.; Lim, J.B.; Klauda, J.B.; Im, W. CHARMM-GUI Membrane Builder for mixed bilayers and its application to yeast membranes. Biophys. J. 2009, 97, 50-58. [CrossRef]

119. Berendsen, H.J.; Postma, J.v.; van Gunsteren, W.F.; DiNola, A.; Haak, J.R. Molecular dynamics with coupling to an external bath. J. Chem. Phys. 1984, 81, 3684-3690. [CrossRef]

120. Bussi, G.; Donadio, D.; Parrinello, M. Canonical sampling through velocity rescaling. J. Chem. Phys. 2007, 126, 014101. [CrossRef]

121. Nosé, S. A molecular dynamics method for simulations in the canonical ensemble. Mol. Phys. 1984, 52, 255-268. [CrossRef]

122. Parrinello, M.; Rahman, A. Crystal structure and pair potentials: A molecular-dynamics study. Phys. Rev. Lett. 1980, $45,1196$. [CrossRef]

123. Darden, T.; York, D.; Pedersen, L. Particle mesh Ewald: An N. $\log (\mathrm{N})$ method for Ewald sums in large systems. J. Chem. Phys. 1993, 98, 10089-10092.

124. Hess, B.; Bekker, H.; Berendsen, H.J.; Fraaije, J.G. LINCS: A linear constraint solver for molecular simulations. J. Comput. Chem. 1997, 18, 1463-1472. [CrossRef]

125. Michaud-Agrawal, N.; Denning, E.J.; Woolf, T.B.; Beckstein, O. MDAnalysis: A toolkit for the analysis of molecular dynamics simulations. J. Comput. Chem. 2011, 32, 2319-2327. [CrossRef] [PubMed]

126. Humphrey, W.; Dalke, A.; Schulten, K. VMD: Visual molecular dynamics. J. Mol. Graph. 1996, 14, 33-38. [CrossRef] 